\title{
State-of-the-art catalysts for direct dehydrogenation of propane to propylene
}

\author{
Zhong-Pan Hu a, Dandan Yang a, Zheng Wang b, Zhong-Yong Yuan a,* \\ a Key Laboratory of Advanced Energy Materials Chemistry (Ministry of Education), Institute of New Catalytic Materials Science, School of Materials \\ Science and Engineering, Nankai University, Tianjin 300350, China \\ b State Key Laboratory of High-Efficiency Utilization of Coal and Green Chemical Engineering, College of Chemistry and Chemical Engineering, Ningxia \\ University, Yinchuan 750021, Ningxia, China
}

\section{A R T I C L E I N F O}

\section{Article history:}

Received 28 January 2019

Accepted 20 March 2019

Published 5 September 2019

\section{Keywords:}

Propane dehydrogenation

Propylene

Heterogeneous catalyst

Active site

Catalytic mechanism

\begin{abstract}
A B S T R A C T
With growing demand for propylene and increasing production of propane from shale gas, the technologies of propylene production, including direct dehydrogenation and oxidative dehydrogenation of propane, have drawn great attention in recent years. In particular, direct dehydrogenation of propane to propylene is regarded as one of the most promising methods of propylene production because it is an on-purpose technique that exclusively yields propylene instead of a mixture of products. In this critical review, we provide the current investigations on the heterogeneous catalysts (such as $\mathrm{Pt}, \mathrm{CrO}_{x}, \mathrm{VO}_{x}, \mathrm{GaO}_{x}$-based catalysts, and nanocarbons) used in the direct dehydrogenation of propane to propylene. A detailed comparison and discussion of the active sites, catalytic mechanisms, influencing factors (such as the structures, dispersions, and reducibilities of the catalysts and promoters), and supports for different types of catalysts is presented. Furthermore, rational designs and preparation of high-performance catalysts for propane dehydrogenation are proposed and discussed.
\end{abstract}

(C) 2019, Dalian Institute of Chemical Physics, Chinese Academy of Sciences. Published by Elsevier B.V. All rights reserved.

\section{Introduction}

Propylene is one of the most important raw materials for the production of many industrial products such as acrolein, polypropene, acetone, polyacrylonitrile, and propylene oxide [1-8]. The traditional industrial processes for propylene production are fluid catalytic cracking and steam cracking of naphtha and light diesels $[1,4]$. With the rapid consumption of fossil-based energy, the traditional methods of propylene production cannot satisfy the growing demand for propylene. The development of an efficient and economic method of propylene production is therefore of great importance, though challenging. Over the last several years, considerable efforts have been made to develop new efficient methods for propylene production, such as propane dehydrogenation (PDH) [1-8], methanol-to-olefins [9,10], and Fischer-Tropsch-to-olefins [11-13]. Among these methods, the PDH technique has been regarded as one of the most promising methods of propylene production, because it is an on-purpose method that exclusively yields propylene, instead of a mixture of products.

Furthermore, with the development of fracking technology, a large amount of shale gas can be extracted by this

\footnotetext{
* Corresponding author. Tel/Fax: +86-22-23509610; E-mail: zyyuan@nankai.edu.cn

This work was supported by the National Natural Science Foundation of China (21421001, 21573115), the Fundamental Research Funds for the Central Universities (63185015), and the Foundation of State Key Laboratory of High-Efficiency Utilization of Coal and Green Chemical Engineering (2017-K13).
}

DOI: S1872-2067(19)63360-7 | http://www.sciencedirect.com/science/journal/18722067 | Chin. J. Catal., Vol. 40, No. 9, September 2019 
cost-effective method; propane is a main constituent of shale gas. The price of propane has decreased obviously, which provides a great opportunity for on-purpose catalytic dehydrogenation of propane to propylene [1,14-16]. Over the last several years, a number of reviews have summarized the oxidative dehydrogenation of alkanes to olefins by using nanocarbons, boron nitride, metals, and metal oxides [2,4,8,14-16]. However, direct dehydrogenation of alkanes to olefins is rarely reported $[1,3,17]$. Particularly, elaborate discussions and comparisons of the origins of the catalytic activities, reaction mechanisms, and functional adjustments of direct PDH catalysts are scarce.

In this work, the state-of-the-art catalysts that have been reported in recent years for direct dehydrogenation of propane to propylene are reviewed. The correlations between the properties and performances of the catalysts are discussed and summarized. Furthermore, the active sites, structural properties, and catalytic mechanisms of $\mathrm{Pt}, \mathrm{CrO}_{x}, \mathrm{VO}_{x}, \mathrm{GaO}_{x}$-based catalysts, and nanocarbons in direct $\mathrm{PDH}$ are analyzed and outlined. The influences of the preparation methods of the catalysts and the types of supports and promoters are highlighted.

\section{Overview of direct PDH}

Direct PDH is a thermodynamically limited highly endothermic process, as observed below $[1,3,17]$.

$$
\mathrm{C}_{3} \mathrm{H}_{8} \rightarrow \mathrm{C}_{3} \mathrm{H}_{6}+\mathrm{H}_{2}\left(\Delta H_{298}^{0}=124.3 \mathrm{~kJ} \cdot \mathrm{mol}^{-1}\right)
$$

It is notable that the $\mathrm{C}-\mathrm{H}$ bonds of propane are highly stable, therefore, a high reaction temperature is required to realize $\mathrm{C}-\mathrm{H}$ bond cleavage. Usually, a high temperature of $\sim 550-700$ ${ }^{\circ} \mathrm{C}$ is needed to achieve a high propane conversion [18-22]. Owing to the absence of oxidizing agents, the propylene selectivity in direct PDH is much higher than that in oxidative dehydrogenation reaction. To date, the direct PDH reaction has been used in industry, such as Catofin (Lummus, $\mathrm{CrO}_{x}$-based catalysts) and Oleflex (UOP, Pt-based catalysts) technologies $[21,23]$.

In direct PDH process, activation of the $\mathrm{C}-\mathrm{H}$ bonds of propane is the most important step that determines the catalytic performance of PDH catalysts. However, the product propylene molecules are more active than propane molecules. Side reactions, including cracking, deep dehydrogenation, and/or polymerization, occur during the PDH process, which result in low selectivity and coke formation [1,5,8,24-27]. Therefore, a good PDH catalyst must favor $\mathrm{C}-\mathrm{H}$ cleavage over $\mathrm{C}-\mathrm{C}$ cleavage. In the past several decades, a number of heterogeneous catalysts (such as $\mathrm{Pt}, \mathrm{CrO}_{x}, \mathrm{VO}_{x}, \mathrm{GaO}_{x}$-based catalysts, and nanocarbons) have been exploited for direct PDH reaction that have exhibited high performances. However, there are still some issues with these catalysts, such as low stability, serious coke formation, high prices, and environmental problems.

\section{Direct PDH catalysts}

\section{1. $\mathrm{CrO}_{x}$-based catalysts}

Supported $\mathrm{CrO}_{x}$ are one of the most efficient catalysts for alkane dehydrogenation that have been studied for several decades $[17,28-37]$. Owing to the low price and high catalytic activity, $\mathrm{CrO}_{x}$-based catalysts have been commercially utilized in Catofin craft $[21,23,24]$. Table 1 lists the recent reports on $\mathrm{CrO}_{x}$-based catalysts for PDH reaction.

On fresh $\mathrm{CrO}_{x}$-based catalysts, there are many kinds of $\mathrm{Cr}$ species, including $\mathrm{Cr}^{6+}, \mathrm{Cr}^{5+}, \mathrm{Cr}^{3+}, \mathrm{Cr}^{2+}$, isolated $\mathrm{Cr}^{n+}$, oligomeric $\mathrm{Cr}^{n+}$, and crystallite $\mathrm{Cr}_{2} \mathrm{O}_{3}$, which play different roles in the $\mathrm{PDH}$ process [30-32]. Rather difficultly, the $\mathrm{Cr}^{6+}$ species would be transformed into $\mathrm{Cr}^{3+}$ and/or $\mathrm{Cr}^{2+}$ during the $\mathrm{PDH}$ process due to the presence of $\mathrm{H}_{2}[30,32]$. Furthermore, the types of supports, $\mathrm{Cr}$ loading amounts, and preparation methods can have great influences on the types of $\mathrm{Cr}$ species present, and thereby, affect the catalytic performances of $\mathrm{CrO}_{x}$-based catalysts [31,33-35]. It is reported that the $\mathrm{Cr}$ species supported on mesoporous silica SBA-15 are isolated $\mathrm{Cr}^{6+}$ at low $\mathrm{Cr}$ loadings $(\leq 1 \%)$, which tend to aggregate into crystalline $\mathrm{Cr}_{2} \mathrm{O}_{3}$ particles as the $\mathrm{Cr}$ loading increases up to $5 \%$ [31]. When the $\mathrm{Cr}$ species are loaded on $\mathrm{Al}_{2} \mathrm{O}_{3}$, a fraction of the isolated and oligomeric $\mathrm{Cr}^{6+}$ species would be present in the $\mathrm{Cr} / \mathrm{Al}_{2} \mathrm{O}_{3}$ catalysts. How-

Table 1

Summary of the catalytic data of $\mathrm{CrO}_{x}$-based catalysts for PDH.

\begin{tabular}{|c|c|c|c|c|c|c|c|c|c|}
\hline Catalyst & $\begin{array}{c}\text { Reaction } \\
\text { temperature }\left({ }^{\circ} \mathrm{C}\right)\end{array}$ & $\begin{array}{l}\text { Flow rate } \\
\text { (mL/min) }\end{array}$ & $\begin{array}{c}\text { Space velocity a } \\
\left(\mathrm{h}^{-1}\right)\end{array}$ & Feed composition & $\begin{array}{c}\text { Conversion b } \\
(\%)\end{array}$ & $\begin{array}{c}\text { Selectivity } \\
\text { (\%) }\end{array}$ & $\begin{array}{l}\text { Space time } \\
\text { yield }^{\mathrm{c}}\left(\mathrm{h}^{-1}\right)\end{array}$ & 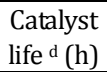 & Ref. \\
\hline $7.5 \mathrm{Cr} / \mathrm{Al}_{2} \mathrm{O}_{3}$ & 600 & 20 & - & $\mathrm{C}_{3} \mathrm{H}_{8} / \mathrm{Ar}=1: 4$ & 62 & 89 & 1.24 & $\sim 2$ & [29] \\
\hline \multirow[t]{3}{*}{$\mathrm{Cr} 20 / \mathrm{Al}_{2} \mathrm{O}_{3}$} & 500 & 30 & $\mathrm{WHSV}=1.2$ & $\mathrm{C}_{3} \mathrm{H}_{8} / \mathrm{He}=1: 14$ & 12.9 & 87.7 & 0.13 & $\sim 4$ & [30] \\
\hline & 550 & 30 & $\mathrm{WHSV}=1.2$ & $\mathrm{C}_{3} \mathrm{H}_{8} / \mathrm{He}=1: 14$ & 33.8 & 94.0 & 0.36 & $\sim 4$ & [30] \\
\hline & 600 & 30 & $\mathrm{WHSV}=1.2$ & $\mathrm{C}_{3} \mathrm{H}_{8} / \mathrm{He}=1: 14$ & 41.8 & 89.8 & 0.42 & $\sim 4$ & [30] \\
\hline $\mathrm{CrZrO}_{x}$ & 550 & $10-60$ & - & $\mathrm{C}_{3} \mathrm{H}_{8} / \mathrm{N}_{2}=2: 3$ & $\sim 30$ & $\sim 85$ & - & 0.8 & [34] \\
\hline \multirow[t]{2}{*}{ Cr20/CMK-3 } & 550 & 30 & $\mathrm{WHSV}=1.2$ & $\mathrm{C}_{3} \mathrm{H}_{8} / \mathrm{He}=1: 14$ & 47.5 & 84.7 & 0.45 & $\sim 4$ & [35] \\
\hline & 600 & 30 & WHSV $=1.2$ & $\mathrm{C}_{3} \mathrm{H}_{8} / \mathrm{He}=1: 14$ & 54.2 & 81.8 & 0.50 & $\sim 4$ & [35] \\
\hline $\mathrm{Cr}-1 / \mathrm{SiO}_{2}$ & 550 & 10 & $\mathrm{GHSV}=353$ & $\mathrm{C}_{3} \mathrm{H}_{8} / \mathrm{Ar}=1: 4$ & $\sim 65$ & 72 & - & $\sim 21$ & [38] \\
\hline $\mathrm{Cr}-1 / \mathrm{SiO}_{2}-\mathrm{Al}_{2} \mathrm{O}_{3}$ & 550 & 10 & $\mathrm{GHSV}=353$ & $\mathrm{C}_{3} \mathrm{H}_{8} / \mathrm{Ar}=1: 4$ & - & $\sim 70$ & - & 25 & [39] \\
\hline $\mathrm{Cr}-1 / \mathrm{Al}_{2} \mathrm{O}_{3}$ & 550 & 10 & $\mathrm{GHSV}=353$ & $\mathrm{C}_{3} \mathrm{H}_{8} / \mathrm{Ar}=1: 4$ & - & $\sim 65$ & - & 25 & [39] \\
\hline CrZr5 & 550 & 30 & $\mathrm{WHSV}=1.2$ & $\mathrm{C}_{3} \mathrm{H}_{8} / \mathrm{He}=1: 14$ & 50.7 & 92.2 & 0.53 & 1 & [41] \\
\hline $2.5 \mathrm{Cr} / \mathrm{Al}$ & 550 & 20 & - & $\mathrm{C}_{3} \mathrm{H}_{8} / \mathrm{Ar}=1: 9$ & 24 & $\sim 95$ & 0.26 & $\sim 3$ & [45] \\
\hline 2.5Cr-Ni/Al & 550 & 20 & - & $\mathrm{C}_{3} \mathrm{H}_{8} / \mathrm{Ar}=1: 9$ & 43 & $\sim 95$ & 0.46 & $\sim 3$ & [45] \\
\hline $17.5 \mathrm{Cr}-2 \mathrm{Ce}-2 \mathrm{~K} / \mathrm{Al}$ & 630 & 80 & - & $\mathrm{C}_{3} \mathrm{H}_{8} / \mathrm{N}_{2}=1: 1$ & $\sim 57.6$ & $\sim 80$ & 10.4 & $<1$ & [46] \\
\hline
\end{tabular}

a WHSV: weight hourly space velocity $\left(\mathrm{h}^{-1}\right)$; GHSV: gas hourly space velocity $\left(\mathrm{h}^{-1}\right) .^{\mathrm{b}}$ Initial propane conversion. ${ }^{\mathrm{c}}$ Defined as (weight of propylene formed) $/($ weight of catalyst $\times t(h))$. ${ }^{d}$ Total time of a single cycle/experiment. 
ever, no crystalline $\mathrm{Cr}_{2} \mathrm{O}_{3}$ particles could be seen over the $\mathrm{Cr} / \mathrm{Al}_{2} \mathrm{O}_{3}$ catalysts even when the $\mathrm{Cr}$ loading is up to $5 \%$. Beak et al. [33] observed that the $\mathrm{Cr}$ species supported on mesoporous silica with a low $\mathrm{Cr}$ content were isolated $\mathrm{Cr}^{6+}$ and polymeric $\mathrm{Cr}^{6+}$. When the $\mathrm{Cr}$ loading exceeds the value of $\mathrm{Cr} / \mathrm{Si}=$ 0.082, a number of crystallite $\mathrm{Cr}_{2} \mathrm{O}_{3}$ particles would be formed. Until now, the preparation of $\mathrm{CrO}_{x}$-based catalysts containing stable and pure $\mathrm{Cr}^{n+}$ species is still a great challenge.

Generally, isolated, unsaturated and/or clustered $\mathrm{Cr}^{3+}$ sites are regarded as the active sites in $\mathrm{CrO}_{x}$-based catalysts for PDH reaction [36,37]. Fig. 1 shows the possible catalytic mechanism of $\mathrm{PDH}$ reaction over $\mathrm{Cr}^{3+}$ catalysts $[38,39]$. Typically, the propane adsorbed would be converted into a $\mathrm{Cr}_{-} \mathrm{C}_{3} \mathrm{H}_{8} \eta^{3}-\mathrm{H}, \mathrm{H}, \mathrm{H}$ adduct. Heterolytic activation of a $\mathrm{C}-\mathrm{H}$ bond yields $\mathrm{Cr}^{3+}-\mathrm{C}_{3} \mathrm{H}_{7}$ intermediate. Subsequently, the $\beta-\mathrm{H}$ in $\mathrm{Cr}^{3+}{ }^{3} \mathrm{C}_{3} \mathrm{H}_{7}$ intermediate would be transformed on $\mathrm{Cr}^{3+}$ to form $\mathrm{Cr}^{3+} \mathrm{C}_{3} \mathrm{H}_{6}$ hydride surface species. Then, propylene would be released and $\mathrm{H}_{2}$ formed, completing the catalytic cycle (Fig. 1a). Besides, byproducts, including methane, ethane, and ethylene, would be formed during the PDH process due to cracking, deep dehydrogenation, and hydrogenation (Fig. 1b and 1c).

\subsubsection{Effect of supports on $\mathrm{CrO}_{x}$-based catalysts}

A series of metal oxides (such as $\mathrm{Al}_{2} \mathrm{O}_{3}, \mathrm{SiO}_{2}$, and $\mathrm{ZrO}_{2}$ ) have been studied as supports of $\mathrm{CrO}_{x}$ catalysts [18,24,28-39]. In these $\mathrm{CrO}_{x}$-based catalysts, the supports play an important role in determining the dispersion (such as isolated $\mathrm{Cr}^{n+}$, oligomeric $\mathrm{Cr}^{n+}$, and crystallite $\mathrm{CrO}_{x}$ species), states (such as $\mathrm{Cr}^{6+}, \mathrm{Cr}^{5+}, \mathrm{Cr}^{3+}$, and $\mathrm{Cr}^{2+}$ ), structure, and electronic properties of the $\mathrm{Cr}$ species, thus affecting their catalytic activity, stability, and anti-coking capability in the $\mathrm{PDH}$ process.

Among these, $\mathrm{Al}_{2} \mathrm{O}_{3}$ is the mostly used support owing to its low price, high thermal stability, good mechanical stability, and strong interactions with $\mathrm{Cr}$ species, which result in improved dispersion, high catalytic stability, and good regenerability of $\mathrm{CrO}_{x} / \mathrm{Al}_{2} \mathrm{O}_{3}$ catalysts $[18,24,28]$. Alternatively, zirconia $\left(\mathrm{ZrO}_{2}\right)$ has been demonstrated to be another efficient support for $\mathrm{Cr}$ catalysts owing to its weak acidity and strong interactions with
$\mathrm{CrO}_{x}$ species. In some case, $\mathrm{CrO}_{x} / \mathrm{ZrO}_{2}$ catalysts exhibit comparable and/or higher activities than $\mathrm{CrO}_{x} / \mathrm{Al}_{2} \mathrm{O}_{3}$ catalysts $[34,40]$. However, a great challenge for these two catalyst systems is the serious coke formation that significantly shortens the catalyst life.

Improving the porosity of $\mathrm{CrO}_{x}$-based catalysts is a good way of improving their performance in $\mathrm{PDH}$. It was reported that $\mathrm{CrO}_{x}$ species supported on mesoporous $\mathrm{Al}_{2} \mathrm{O}_{3}$ exhibited enhanced activity in the PDH process due to the presence of many mesopores and highly dispersed $\mathrm{Cr}$ species [29]. A series of highly ordered mesoporous $\mathrm{Cr} / \mathrm{Al}_{2} \mathrm{O}_{3}$ and $\mathrm{Cr}-\mathrm{Zr}-\mathrm{O}$ catalysts with narrow pore size distributions were synthesized by nanocasting method using CMK-3 as a hard template $[30,41]$, and the resulting ordered mesoporous $\mathrm{CrO}_{x} / \mathrm{Al}_{2} \mathrm{O}_{3}$ and $\mathrm{Cr}-\mathrm{Zr}-\mathrm{O}$ catalysts exhibited enhanced resistances to deactivation in $\mathrm{PDH}$, compared to those of $\mathrm{CrO}_{x}$ catalysts supported on commercial $\mathrm{Al}_{2} \mathrm{O}_{3}$ and bulk $\mathrm{ZrO}_{2}$. Besides, enhanced catalytic performance in $\mathrm{PDH}$ reaction was also achieved for $\mathrm{CrO}_{x}$ catalysts supported on ordered mesoporous carbons (CMK-3) [35]. Owing to the presence of highly ordered mesopores in $\mathrm{Cr} / \mathrm{Al}_{2} \mathrm{O}_{3}$, Cr-Zr-O, and $\mathrm{Cr} / \mathrm{CMK}-3$ catalysts, local transport limitations can be avoided during the PDH process. Therefore, the prepared mesoporous Cr-based catalysts exhibit enhanced activity, selectivity, and stability in PDH.

Introducing secondary metal oxides into $\mathrm{Al}_{2} \mathrm{O}_{3}$ and/or $\mathrm{ZrO}_{2}$ support is another efficient method of improving the performances of Cr-based catalysts in PDH, because it can decrease the acidity of the as-synthesized catalysts and affect the dispersion and states of the $\mathrm{Cr}$ species. Kim et al. [42] reported that the distribution of $\mathrm{CrO}_{x}$ species was strongly dependent on the $\mathrm{Zr} / \mathrm{Al}$ ratio. The addition of a certain amount of $\mathrm{Zr}$ species $(\mathrm{Zr} / \mathrm{Al}=0.07)$ to $\mathrm{Al}_{2} \mathrm{O}_{3}$ could increase the amounts of active $\mathrm{Cr}^{3+}$ species and decrease $\alpha$-chromia-alumina, thus increasing the activity of $\mathrm{CrO}_{x}$-based catalysts. Furthermore, Sim et al. [43] found that the introduction of $\mathrm{ZrO}_{2}$ in $\mathrm{Al}_{2} \mathrm{O}_{3}$ support could greatly suppress the formation of chromia/alumina solid solution, and thereby improve the activity and thermal stability of $\mathrm{CrO}_{x}$-based catalysts.
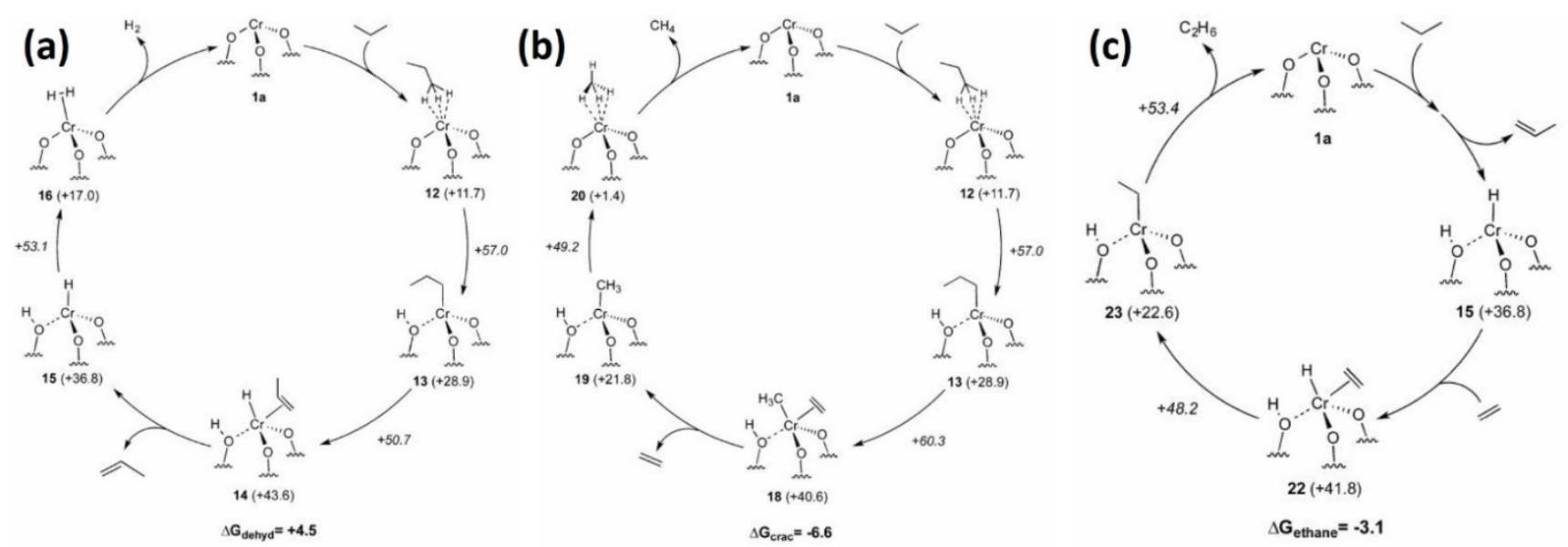

Fig. 1. (a) Possible $\mathrm{PDH}$ process over $\mathrm{Cr}-1 / \mathrm{SiO}_{2}$. (b) Generation of byproducts (methane and ethylene) during the $\mathrm{PDH}$ process over the $\mathrm{Cr}-1 / \mathrm{SiO}{ }_{2}$ catalyst. (c) Formation of ethane over the $\mathrm{Cr}-1 / \mathrm{SiO}_{2}$ catalyst during the PDH process. The numbers in parentheses are the Gibbs free energies of the corresponding intermediates, and those on the arrows are the Gibbs free energies of the transition states, normalized with respect to that of $\mathrm{Cr}-1 / \mathrm{SiO}_{2}$ + propane. All the energies are given in $\mathrm{kcal} \mathrm{mol}^{-1}$ [38]. 
Indeed, a number of novel supports (such as mesoporous $\mathrm{Al}_{2} \mathrm{O}_{3}$, mesoporous $\mathrm{ZrO}_{2}$, and $\mathrm{Al}_{2} \mathrm{O}_{3}-\mathrm{ZrO}_{2}$ ) have been exploited for the preparation of $\mathrm{Cr}$-based catalysts that exhibit enhanced performances in PDH. However, there are still some drawbacks, such as serious side reactions (cracking, deep dehydrogenation, and coke formation), with these catalysts. In particular, their catalytic activities decrease obviously after times-on-stream of only several hours, as shown in Table 1 . The exploitation of new efficient supports for improving the stability of Cr-based catalysts is still a great challenge.

\subsubsection{Effect of promoters on $\mathrm{CrO}_{x}$-based catalysts}

Although metal oxides (such as $\mathrm{Al}_{2} \mathrm{O}_{3}$ and $\mathrm{ZrO}_{2}$ ) have been widely studied as supports for $\mathrm{CrO}_{x}$ catalysts, the stability of $\mathrm{CrO}_{x}$-based catalysts is still too low. To improve their performances, promoters (such as $\mathrm{K}, \mathrm{Ce}, \mathrm{Ni}$, and $\mathrm{Sn}$ ) are introduced into the $\mathrm{CrO}_{x}$-based catalysts $[40,41,42-45]$. After the addition, their structure and surface properties would be greatly changed, which would have a great influence on their catalytic performance in PDH.

Alkali metals such as $\mathrm{K}, \mathrm{Na}, \mathrm{Ca}$, and $\mathrm{Mg}$ have been widely used as promoters to poison the acidic sites of heterogeneous catalysts, and thereby, improve their selectivity and stability in the PDH process. In the earlier studies on $\mathrm{CrO}_{x}$-based catalysts, the widely used alkali metal was $\mathrm{K}[40,41]$. K-modified $(0.2 \%$, $0.5 \%$, or $1 \%$ ) $\mathrm{Cr}-\mathrm{Zr}-0$ catalysts exhibit enhanced propylene selectivity and resistance to coke deposition in PDH reaction, compared with pristine $\mathrm{Cr}-\mathrm{Zr}-\mathrm{O}$ [41]. It is revealed that the addition of a $\mathrm{K}$ species can greatly decrease the acidity of $\mathrm{Cr}-\mathrm{Zr}-\mathrm{O}$ catalysts, thus decreasing the deactivation rate and coke formation. However, the addition of K species would also poison some Lewis acid sites, which has a negative impact on the PDH process. Cutrufello et al. [40] found that the activity of $\mathrm{CrO}_{x} / \mathrm{ZrO}_{x}$ catalyst after addition of $\mathrm{K} \geq 1 \mathrm{wt} \%$ was almost zero for PDH reaction. This is due to the fact that the $\mathrm{K}$ species hinder the reduction of $\mathrm{Cr}^{6+}$ to the active $\mathrm{Cr}^{3+}$ species and decrease the Lewis acid sites of $\mathrm{Cr}^{3+}$ in $\mathrm{Cr}^{3+}-\mathrm{O}^{2-}$ acid-base couples, which are the possible sites for propane activation. Alkali metals can poison some strong acid sites of the catalysts, and thereby, increase the selectivity and anti-coking capability of $\mathrm{CrO}_{x}$-based catalysts in PDH. However, some of the Lewis acid sites would also be poisoned after the addition of alkali metals, which has a negative influence on the PDH process. The development of a selective promoter that improves the activity, selectivity, and anti-coking capability of $\mathrm{CrO}_{x}$-based catalysts is still ongoing.

Transition metal species have also been studied as promoters for $\mathrm{CrO}_{x}$-based catalysts. Different from alkali metals, transition metals have little influence on the acidic properties of $\mathrm{CrO}_{x}$-based catalysts. However, they play an important role in influencing the dispersion, oxygen capacity, and surface properties of $\mathrm{CrO}_{x}$-based catalysts, thus affecting their PDH performance. Cabrera et al. [44] reported that introducing a certain amount of $\mathrm{Sn}$ into the $\mathrm{CrO}_{x} / \mathrm{Al}_{2} \mathrm{O}_{3}$ catalyst can greatly decrease the coking formation during the $\mathrm{PDH}$ process. It is revealed that the addition of $\mathrm{Sn}$ species results in an important change in the amount of oxidized $\mathrm{Cr}$ species, which improves the activity, selectivity, and stability of $\mathrm{CrO}_{x} / \mathrm{Al}_{2} \mathrm{O}_{3}$ catalysts. Furthermore, addition of $\mathrm{Ni}$ species can promote the formation of oligomeric $\mathrm{Cr}$ species and affects the valence of the surface $\mathrm{Cr}$ species present on supports, thus improving the performances of $\mathrm{CrO}_{x} / \mathrm{Al}_{2} \mathrm{O}_{3}$ catalysts [45]. Besides, $\mathrm{Ce}, \mathrm{Sb}, \mathrm{Co}$, and $\mathrm{Bi}$ have been added to $\mathrm{CrO}_{x} / \mathrm{Al}_{2} \mathrm{O}_{3}$ catalysts [45-48]. The addition of these metal species can affect the oxygen capacity and magnetic properties of $\mathrm{CrO}_{x}$-based catalysts, which can positively contribute to the PDH process.

In summary, the performances of $\mathrm{CrO}_{x}$-based catalysts are strongly affected by the preparation methods, natures of supports and promoters, structures of catalysts, and active sites present in the catalysts. Generally, $\mathrm{CrO}_{x}$ catalysts supported on traditional supports (such as $\mathrm{Al}_{2} \mathrm{O}_{3}, \mathrm{SiO}_{2}$, and $\mathrm{ZrO}_{2}$ ) display small surface areas and pore volumes, and exhibit low catalytic stability in PDH reaction. To improve the catalytic performance, novel supports (such as SBA-15, ordered mesoporous $\mathrm{Al}_{2} \mathrm{O}_{3}$, and mesoporous carbon) with ordered mesopores have been used for $\mathrm{CrO}_{x}$ catalysts. Ordered mesostructures of supports have the advantages of well-controlled morphologies, high surface areas, and rich pores, which are good for mass transportation and can provide more accessible active sites. However, syntheses of these supports are time-consuming, complex, and expensive, and cannot be widely employed in industry. Furthermore, the active sites and mechanisms of these catalysts are hard to identify owing to their heterogeneous structures in microfields. Alternatively, novel methods (such as surface-organometallic-chemistry method) have been used for the synthesis of isolated $\mathrm{Cr}$ catalysts. Owing to their well-defined structure, the catalytic mechanism could be easily identified. On the basis of the abovementioned advantages and disadvantages of $\mathrm{CrO}_{x}$-based catalysts, it can be concluded that a good $\mathrm{CrO}_{x}$-based catalyst in $\mathrm{PDH}$ reaction must contain well-defined pores (which aid mass transport), display a high surface area (i.e., supply more accessible active sites), and exhibit suitable acidity (to avoid cracking and deep dehydrogenation). Possibly, zeolites (with well-defined pores and controlled acidities) and mixed metal oxides (with high surface areas and low acidities) are promising supports for $\mathrm{Cr}$ catalysts in PDH reaction.

Furthermore, the addition of promoters (such as $\mathrm{Li}, \mathrm{Na}, \mathrm{K}$, $\mathrm{Sn}, \mathrm{Co}$, and Ce) can strongly affect the performances of $\mathrm{CrO}_{x}$-based catalysts in PDH. Alkali metals (such as $\mathrm{Li}, \mathrm{Na}$, and K) can curb the acidity of the support and suppress the formation of coke on the catalyst. However, some of the Lewis acid sites would be poisoned after the addition of alkali metals, which would result in a decrease in the catalytic activity. Alternatively, transition metals can be utilized as promising promoters for $\mathrm{CrO}_{x}$-based catalysts. Transition metals can improve the distribution of $\mathrm{Cr}$ species, decrease the acidity of supports, moderate the surface properties of the $\mathrm{Cr}$ species, and have little influence on the Lewis acid sites of $\mathrm{CrO}_{x}$-based catalysts, thus improving their activity, selectivity, stability, and anti-coking capability in PDH.

\subsection{Pt-based catalysts}

Pt-based catalysts are the most widely used PDH catalysts that have been commercially employed in Oleflex (UOP) craft 
[21,23,49-51]. Compared with $\mathrm{CrO}_{x}$-based catalysts, Pt-based catalysts display many advantages such as eco-friendliness and high stability. However, this catalyst system still suffers from deactivation and coke formation. Particularly, the sintering of Pt during the PDH would result in irreversible deactivation. Great efforts have been made to improve the activity and stability of Pt catalysts by loading them onto porous supports, which results in changes to several properties (such as dispersion, reducibility, structure, and electronic properties) of the Pt species that have a great influence on their performance. Table 2 lists the recently reported Pt-based catalysts for PDH reaction.

In Pt-based catalysts, the size and structure of the Pt nanoparticles can greatly influence their activity, selectivity, stabil- ity, and the mechanism of the PDH process. Zhu et al. [52] synthesized a series of Pt nanoparticles with the sizes of 3-9 nm that were subsequently supported on $\mathrm{Mg}(\mathrm{Al}) \mathrm{O}$. It was found that the propane conversion of Pt catalysts decreased with increasing Pt particle size. Particularly, the Pt particles with small sizes and (211)-dominating crystal planes revealed a low dehydrogenation energy barrier and a high catalytic activity. On the other hand, large particles with Pt (111)-dominating crystal planes exhibited a high energy barrier for $\mathrm{C}-\mathrm{H}$ bond activation. Besides, the composition of the carrier gas can influence the performances of Pt-based catalysts, because $\mathrm{H}_{2}$ can decrease the coverage of deeply dehydrogenated coke precursors on the surface of active sites [53]. Thus, the generated propylene can be easily desorbed from the surface of Pt to

Table 2

Summary of the data of Pt-based catalysts for PDH.

\begin{tabular}{|c|c|c|c|c|c|c|c|c|c|}
\hline Catalyst & $\begin{array}{c}\text { Reaction } \\
\text { temperature } \\
\left({ }^{\circ} \mathrm{C}\right)\end{array}$ & $\begin{array}{c}\text { Flow } \\
\text { rate } \\
(\mathrm{mL} / \mathrm{min})\end{array}$ & $\begin{array}{c}\text { Space } \\
\text { velocity a } \\
\left(\mathrm{h}^{-1}\right) \\
\end{array}$ & Feed composition & $\begin{array}{c}\text { Conversion }{ }^{\mathrm{b}} \\
(\%)\end{array}$ & $\begin{array}{c}\text { Selectivity }{ }^{\mathrm{c}} \\
(\%)\end{array}$ & $\begin{array}{l}\text { Space time } \\
\text { yield d }^{\mathrm{d}} \\
\left(\mathrm{h}^{-1}\right)\end{array}$ & $\begin{array}{c}\text { Catalyst } \\
\text { life e } \\
\text { (h) }\end{array}$ & Ref. \\
\hline $\mathrm{Pt}-\mathrm{Sn} / \mathrm{MgAl}_{2} \mathrm{O}_{4}$ & 575 & 76.15 & WHSV $=14.7$ & $\mathrm{C}_{3} \mathrm{H}_{8} / \mathrm{H}_{2}=5: 4$, balance $\mathrm{Ar}$ & $\sim 33-29$ & $\sim 99$ & 4.58 & 3.3 & {$[50]$} \\
\hline Pt-Sn/ZSM-5 & 590 & - & WHSV = 3.0 & $\mathrm{C}_{3} \mathrm{H}_{8} / \mathrm{H}_{2}=4: 1$ & $33.1-26.3$ & $47.7-56.4$ & 0.45 & 6 & {$[54]$} \\
\hline $\mathrm{Pt}-\mathrm{Sn} / \gamma-\mathrm{Al}_{2} \mathrm{O}_{3}$ & 590 & - & WHSV = 3.0 & $\mathrm{C}_{3} \mathrm{H}_{8} / \mathrm{H}_{2}=4: 1$ & $29.4-22.7$ & $\sim 90$ & 0.76 & 6 & {$[54]$} \\
\hline $\mathrm{Pt}-\mathrm{Sn} /$ mesoporous $\mathrm{Al}_{2} \mathrm{O}_{3}$ & 590 & - & WHSV $=3.0$ & $\mathrm{C}_{3} \mathrm{H}_{8} / \mathrm{H}_{2}=4: 1$ & $29.8-24.6$ & $\sim 90$ & 0.77 & 6 & {$[54]$} \\
\hline Pt-Sn/SBA-15 & 590 & - & WHSV = 3.0 & $\mathrm{C}_{3} \mathrm{H}_{8} / \mathrm{H}_{2}=4: 1$ & $\sim 11.0-6.0$ & $\sim 90$ & 0.28 & 6 & {$[54]$} \\
\hline $\mathrm{Pt} / \mathrm{Al}_{2} \mathrm{O}_{3}$ sheet & 590 & - & WHSV = 9.4 & $\mathrm{C}_{3} \mathrm{H}_{8} / \mathrm{H}_{2} / \mathrm{N}_{2}=1: 1.25: 4$ & $42.7-15.9$ & 95.7 & 3.67 & 24 & {$[55]$} \\
\hline \multirow[t]{2}{*}{$\mathrm{PtSn} / \mathrm{Al}_{2} \mathrm{O}_{3}$ sheet } & 590 & - & WHSV = 9.4 & $\mathrm{C}_{3} \mathrm{H}_{8} / \mathrm{H}_{2} / \mathrm{N}_{2}=1: 1.25: 4$ & $48.7-44.6$ & 99.1 & 4.33 & 24 & {$[55]$} \\
\hline & 590 & - & WHSV $=56.5$ & $\mathrm{C}_{3} \mathrm{H}_{8} / \mathrm{H}_{2} / \mathrm{N}_{2}=1: 1.25: 4$ & $28.9-27.2$ & 99.5 & 15.5 & 24 & {$[55]$} \\
\hline $2 \mathrm{Pt}-0.6 \mathrm{Sn} / \gamma-\mathrm{Al}_{2} \mathrm{O}_{3}$ & 540 & 50 & - & $\mathrm{C}_{3} \mathrm{H}_{8} / \mathrm{H}_{2} / \mathrm{N}_{2}=6: 2: 42$ & $42.9-39.2$ & 97.5 & 1.41 & 8 & [57] \\
\hline $2 \mathrm{Pt}-1.2 \mathrm{Sn} /-\mathrm{Al}_{2} \mathrm{O}_{3}$ & 540 & 50 & - & $\mathrm{C}_{3} \mathrm{H}_{8} / \mathrm{H}_{2} / \mathrm{N}_{2}=6: 2: 42$ & $43.5-41.4$ & 99.1 & 1.45 & 8 & {$[57]$} \\
\hline $2 \mathrm{Pt}-2.4 \mathrm{Sn} / \gamma-\mathrm{Al}_{2} \mathrm{O}_{3}$ & 540 & 50 & - & $\mathrm{C}_{3} \mathrm{H}_{8} / \mathrm{H}_{2} / \mathrm{N}_{2}=6: 2: 42$ & $42.8-41.7$ & 99.4 & 1.44 & 8 & {$[57]$} \\
\hline $2 \mathrm{Pt}-3.6 \mathrm{Sn} / \gamma-\mathrm{Al}_{2} \mathrm{O}_{3}$ & 540 & 50 & - & $\mathrm{C}_{3} \mathrm{H}_{8} / \mathrm{H}_{2} / \mathrm{N}_{2}=6: 2: 42$ & $42.8-41.8$ & 99.4 & 1.44 & 8 & {$[57]$} \\
\hline $\mathrm{Pt} / \mathrm{TiO}_{2}-\mathrm{Al}_{2} \mathrm{O}_{3}$ & 600 & 50 & WHSV = 10 & $\mathrm{C}_{3} \mathrm{H}_{8} / \mathrm{H}_{2} / \mathrm{N}_{2}=13: 13: 24$ & $47.3-25.9$ & 92.2 & 4.16 & 10 & {$[58]$} \\
\hline $\mathrm{Pt} / \mathrm{Mg}(\mathrm{Zn}) \mathrm{AlO}_{x}$ & 550 & - & WHSV = 8 & $\mathrm{C}_{3} \mathrm{H}_{8} / \mathrm{H}_{2}=4: 1$ & 19 & $\sim 99.3$ & 1.44 & - & {$[60]$} \\
\hline PtIn/Mg(Al)O-x & 620 & - & WHSV = 3.3 & $\mathrm{C}_{3} \mathrm{H}_{8} / \mathrm{H}_{2} / \mathrm{Ar}=8: 7: 35$ & $66.4-43.5$ & 95 & 1.99 & 8 & {$[62]$} \\
\hline $\mathrm{Pt} / \mathrm{CeAl}$ & 600 & 50 & WHSV $=10$ & $\mathrm{C}_{3} \mathrm{H}_{8} / \mathrm{H}_{2}=1: 1$, balance $\mathrm{N}_{2}$ & $47.1-22.2$ & 86.0 & 3.87 & 15 & {$[63]$} \\
\hline $\mathrm{Pt} 3 \mathrm{Ga} / \mathrm{Al}_{2} \mathrm{O}_{3}$ & 600 & 50 & WHSV $=10$ & $\mathrm{C}_{3} \mathrm{H}_{8} / \mathrm{H}_{2}=1: 1$, balance $\mathrm{N}_{2}$ & $39.4-28.1$ & 99.5 & 3.74 & 15 & {$[63]$} \\
\hline Pt3Ga/CeAl & 600 & 50 & WHSV $=10$ & $\mathrm{C}_{3} \mathrm{H}_{8} / \mathrm{H}_{2}=1: 1$, balance $\mathrm{N}_{2}$ & $41.1-32.2$ & 99.6 & 3.91 & 15 & {$[63]$} \\
\hline PtSnIn/08Zr-Al & 600 & - & WHSV = 3.3 & $\mathrm{C}_{3} \mathrm{H}_{8} / \mathrm{H}_{2} / \mathrm{Ar}=8: 7: 35$ & 55.0 & 98.0 & 1.70 & 2.5 & {$[64]$} \\
\hline $\mathrm{PtSnAl}_{0.2} / \mathrm{SBA}-15$ & 590 & - & WHSV $=2.5$ & $\mathrm{C}_{3} \mathrm{H}_{8} / \mathrm{Ar}=1: 5$ & $55.9-40.5$ & 98.5 & 1.31 & 6 & {$[66]$} \\
\hline Pt-Sn/SAPO-34-500 & 595 & - & WHSV = 5.6 & $\mathrm{C}_{3} \mathrm{H}_{8} / \mathrm{H}_{2}=4: 1$ & 34.63 & 93.11 & 1.72 & 8 & {$[67]$} \\
\hline PtNa/Zn(1.0\%)-ZSM-5 & 590 & - & WHSV = 3.0 & $\mathrm{C}_{3} \mathrm{H}_{8} / \mathrm{H}_{2}=4: 1$ & 40.6 & $\sim 96$ & 1.12 & 10 & [68] \\
\hline PtSn/TS-1 & 600 & - & WHSV = 3 & $\mathrm{C}_{3} \mathrm{H}_{8} / \mathrm{H}_{2} / \mathrm{N}_{2}=1: 1: 4$ & $53.5-47.7$ & $\sim 92.5$ & 1.42 & 7 & {$[20]$} \\
\hline $\mathrm{Pt}-\mathrm{Sn}-2 / \mathrm{MgAl}_{2} \mathrm{O}_{4}$ & 580 & 20 & - & $\mathrm{C}_{3} \mathrm{H}_{8} / \mathrm{H}_{2} / \mathrm{He}=1: 1: 8$ & 45-18.7 & $94-98.3$ & 0.95 & 90 & {$[74]$} \\
\hline $\mathrm{Pt}-\mathrm{Sn}-3 / \mathrm{MgAl}_{2} \mathrm{O}_{4}$ & 580 & 20 & - & $\mathrm{C}_{3} \mathrm{H}_{8} / \mathrm{H}_{2} / \mathrm{He}=1: 1: 8$ & 18.7 & 98.3 & 0.41 & 90 & {$[74]$} \\
\hline $\mathrm{Pt}-\mathrm{Sn}-4 / \mathrm{MgAl}_{2} \mathrm{O}_{4}$ & 580 & 20 & - & $\mathrm{C}_{3} \mathrm{H}_{8} / \mathrm{H}_{2} / \mathrm{He}=1: 1: 8$ & 31.5 & 99.6 & 0.71 & 90 & {$[74]$} \\
\hline $\mathrm{Pt}-\mathrm{Sn}-5 / \mathrm{MgAl}_{2} \mathrm{O}_{4}$ & 580 & 20 & - & $\mathrm{C}_{3} \mathrm{H}_{8} / \mathrm{H}_{2} / \mathrm{He}=1: 1: 8$ & $45-37.6$ & 99.5 & 1.01 & 90 & {$[74]$} \\
\hline Pt-Sn-6/ $\mathrm{MgAl}_{2} \mathrm{O}_{4}$ & 580 & 20 & - & $\mathrm{C}_{3} \mathrm{H}_{8} / \mathrm{H}_{2} / \mathrm{He}=1: 1: 8$ & $45-38.9$ & 99.7 & 1.01 & 90 & {$[74]$} \\
\hline \multirow[t]{2}{*}{0.5 wt\%Pt/Mg(Sn)(Al)O } & 550 & - & WHSV = 14 & $\mathrm{C}_{3} \mathrm{H}_{8} / \mathrm{H}_{2} / \mathrm{Ar}=1: 0.5: 2$ & $29.4-27.8$ & $93.7-99.2$ & 3.68 & 240 & {$[75]$} \\
\hline & 600 & - & WHSV = 14 & $\mathrm{C}_{3} \mathrm{H}_{8} / \mathrm{H}_{2} / \mathrm{Ar}=1: 0.5: 2$ & $48.3-43.0$ & $86.4-98.1$ & 5.57 & 48 & [75] \\
\hline Pt/0.5Sn-SBA-15 & 580 & - & WHSV $=8.25$ & $\mathrm{C}_{3} \mathrm{H}_{8} / \mathrm{Ar}=7: 3$ & 43.8 & 98.5 & 3.40 & 6 & {$[77]$} \\
\hline $\mathrm{Pt}-\mathrm{Sn} / \mathrm{SiO}_{2} \_1073 \mathrm{~K} \mathrm{H}_{2}$ & 500 & 100 & WHSV = 47 & $\mathrm{C}_{3} \mathrm{H}_{8} / \mathrm{N}_{2}=1: 4$ & 27.0 & 99.5 & 12.1 & 3 & {$[80]$} \\
\hline $15 \% \mathrm{Zn}-0.1 \% \mathrm{Pt} / \mathrm{Al}_{2} \mathrm{O}_{3}$ & 600 & 50 & WHSV = 3 & $\mathrm{C}_{3} \mathrm{H}_{8} / \mathrm{H}_{2}=1: 1$, balance $\mathrm{N}_{2}$ & $35-31$ & $94-97$ & 0.94 & 4 & {$[84]$} \\
\hline 0.3PtSn/1.5In-Al & 620 & - & GHSV $=1500$ & $\mathrm{C}_{3} \mathrm{H}_{8} / \mathrm{H}_{2} / \mathrm{Ar}=8: 7: 35$ & $58.4-48.6$ & 92.8 & - & 2.75 & {$[90]$} \\
\hline PtIn/Mg(Al)O-600 & 620 & - & WHSV = 3.3 & $\mathrm{C}_{3} \mathrm{H}_{8} / \mathrm{H}_{2} / \mathrm{Ar}=8: 7: 35$ & 69.0 & 98.0 & 2.13 & 30 & [91] \\
\hline \multirow[t]{3}{*}{$\mathrm{Ga}^{\delta+} \mathrm{Pt}^{0} / \mathrm{SiO}_{2}$} & 550 & 50 & WHSV = 98.3 & $\mathrm{C}_{3} \mathrm{H}_{8} / \mathrm{Ar}=1: 4$ & $31.9-18.2$ & 99 & 29.6 & 20 & [19] \\
\hline & 550 & 50 & WHSV $=43.3$ & $\mathrm{C}_{3} \mathrm{H}_{8} / \mathrm{Ar}=1: 4$ & $36.5-26.9$ & $90.9-82.8$ & 13.71 & 20 & [19] \\
\hline & 550 & 50 & WHSV = 2.0 & $\mathrm{C}_{3} \mathrm{H}_{8} / \mathrm{Ar}=1: 4$ & $40.7-38.5$ & $63.5-70.1$ & 0.49 & 20 & [19] \\
\hline $0.1 \mathrm{Pt} 10 \mathrm{Cu} / \mathrm{Al}_{2} \mathrm{O}_{3}$ & 520 & 50 & WHSV = 4 & $\mathrm{C}_{3} \mathrm{H}_{6} / \mathrm{H}_{2} / \mathrm{N}_{2}=4: 4: 17$ & 13.1 & 90 & 0.45 & 120 & {$[92]$} \\
\hline $\mathrm{Pt}-\mathrm{Cu} / \mathrm{MgAl}_{2} \mathrm{O}_{4}$ & 580 & 40 & WHSV $=6.8$ & $\mathrm{C}_{3} \mathrm{H}_{6} / \mathrm{H}_{2} / \mathrm{Ar}=19: 19: 1$ & $25.7-21.0$ & $87.5-93.1$ & 1.46 & 24 & [95] \\
\hline $\mathrm{Pt}-\mathrm{Ag} / \mathrm{MgAl}_{2} \mathrm{O}_{4}$ & 580 & 40 & WHSV $=6.8$ & $\mathrm{C}_{3} \mathrm{H}_{6} / \mathrm{H}_{2} / \mathrm{Ar}=19: 19: 1$ & $30.6-16.7$ & $85.1-95.0$ & 1.69 & 24 & [95] \\
\hline $\mathrm{Pt}-\mathrm{Au} / \mathrm{MgAl}_{2} \mathrm{O}_{4}$ & 580 & 40 & WHSV = 6.8 & $\mathrm{C}_{3} \mathrm{H}_{6} / \mathrm{H}_{2} / \mathrm{Ar}=19: 19: 1$ & $33.7-16.6$ & $60.0-88.2$ & 1.31 & 24 & [95] \\
\hline
\end{tabular}

a WHSV: weight hourly space velocity $\left(\mathrm{h}^{-1}\right)$; GHSV: gas hourly space velocity $\left(\mathrm{h}^{-1}\right) \mathrm{e}^{\mathrm{b}, \mathrm{c}}$ The first value is obtained at the start of the cycle, and the second at the end. ${ }^{\mathrm{d}}$ Defined as (weight of propylene formed)/(weight of catalyst $\times t(\mathrm{~h})$ ). ${ }^{\mathrm{e}}$ Total time of a single cycle/experiment. 
avoid side reactions such as cracking and coke formation.

\subsubsection{Effect of supports on Pt-based catalysts}

In Pt-based catalysts, the support plays an important role in determining the dispersion, stability, and structural and electronic properties of the Pt particles. During the PDH process, the high reaction temperature would result in the growth of $\mathrm{Pt}$ particles, which would have a negative impact on the PDH process. Therefore, a good support for Pt-based catalysts should stabilize the Pt species. A number of supports (such as $\mathrm{Al}_{2} \mathrm{O}_{3}$, $\mathrm{SiO}_{2}, \mathrm{TiO}_{x}-\mathrm{Al}_{2} \mathrm{O}_{3}, \mathrm{MgAl}_{2} \mathrm{O}_{4}, \mathrm{Mg}(\mathrm{Zn}) \mathrm{AlO}_{x}, \mathrm{Mg}(\mathrm{Ga})(\mathrm{Al}) \mathrm{O}$, mixed oxides, zeolites, and nanocarbons) have been studied for PDH catalysts [19-20,49-95].

Among these, $\mathrm{Al}_{2} \mathrm{O}_{3}$ is the mostly used support for Pt catalysts owing to its high thermal stability, rich pores, low price, and high mechanical strength. Zhang et al. [54] investigated the influences of different supports (ZSM-5, $\gamma-\mathrm{Al}_{2} \mathrm{O}_{3}$, mesoporous alumina, and SBA-15) on the performances of Pt-Sn catalysts in $\mathrm{PDH}$. It was found that Pt-Sn supported on $\gamma-\mathrm{Al}_{2} \mathrm{O}_{3}$ and mesoporous alumina exhibit high catalytic activities and selectivities for PDH. However, Pt-Sn supported on SBA-15 and HZSM-5 display really low activities and selectivities, respectively. This is due to the presence of a weak interaction between SBA-15 and Pt-Sn. In particular, the high acidity of HZSM-5 would result in cracking and deep dehydrogenation, which have a negative influence on PDH. To improve the interactions between $\mathrm{Pt}$ and the $\mathrm{Al}_{2} \mathrm{O}_{3}$ support, some novel and/or modified $\mathrm{Al}_{2} \mathrm{O}_{3}$ supports are used for the preparation of Pt-based catalysts. Shi et al. [55] synthesized $\mathrm{Al}_{2} \mathrm{O}_{3}$ nanosheets with pentacoordinate $\mathrm{Al}^{3+}$ as supports for Pt-Sn clusters. The pentacoordinate $\mathrm{Al}^{3+}$ species can well disperse and stabilize raft-like Pt-Sn clusters, and guarantees high activity and stability. However, $\mathrm{Al}_{2} \mathrm{O}_{3}$ exhibits a high acidity, which can lead to deep dehydrogenation, cracking, and coke formation [56,57].

In order to decrease the acidity of $\mathrm{Al}_{2} \mathrm{O}_{3}$, a non-acidic metal oxide needs to be introduced. It is reported that the addition of $\mathrm{TiO}_{2}$ species to $\mathrm{Al}_{2} \mathrm{O}_{3}$ support can improve the stability of Pt-based catalysts. The introduction of $\mathrm{TiO}_{2}$ can increase the electron density of $\mathrm{Pt}$, and thus, reduce the adsorption of propylene and improve the stability [58]. Alternatively, $\mathrm{MgO}$ species can be introduced into $\mathrm{Al}_{2} \mathrm{O}_{3}$ support. Shan et al. found that Pt-Sn supported on $\mathrm{MgAl}_{2} \mathrm{O}_{4}$ exhibited high catalytic activity and long-term stability for PDH owing to the hierarchical structure and weak acidity [50]. Furthermore, $\mathrm{Mg}(\mathrm{Ga})(\mathrm{Al}) \mathrm{O}$ [59], $\mathrm{Mg}(\mathrm{Zn}) \mathrm{AlO}_{x}$ [60], $\mathrm{Mg}, \mathrm{Al}$, In-containing layered double hydroxides [61], and $\mathrm{In} / \mathrm{Mg}(\mathrm{Al}) \mathrm{O}-\mathrm{x}$ [62] materials are used as supports in the preparation of Pt-based catalysts that exhibit enhanced catalytic stability and anti-coking capability for PDH. This is due to the changes in the structure, acidity, surface, and electronic properties of Pt-based catalysts. Particularly, the decrease in the acidity of the support is good for the desorption of the product propylene, and thus, leads to enhanced catalytic stability and anti-coking capability. Additionally, other metal oxides (such as $\mathrm{CeO}_{2}, \mathrm{ZrO}_{2}$, and $\mathrm{SiO}_{2}$ ) are also introduced into $\mathrm{Al}_{2} \mathrm{O}_{3}$ support [63-66]. After mixing with these metal oxides, the activity, stability, and anti-coking capability of Pt-based catalysts would be greatly improved, due to the increased in- teractions between $\mathrm{Pt}$ and the supports, which improve the dispersion, decrease the acidity, and moderate the electronic properties of Pt catalysts.

Zeolites have been reported as promising supports for Pt-based catalysts for PDH owing to their well-defined pores, high surface areas, and tunable acidities. Nawaz et al. [67] reported that Pt-Sn supported on SAPO-34 exhibited a high catalytic activity for PDH. However, calcination temperature can affect the performance of Pt-based catalysts. After calcination at high temperatures, the structure of SAPO- 34 would be changed, which leads to a decrease in the catalytic activity. Alternatively, ZSM-5 zeolites display high thermal stability, and can be used as a promising support for Pt species. Zhang et al. [68] reported that Pt supported on Zn-modified ZSM-5 exhibited high activity and stability for PDH. However, the high acidity of ZSM-5 support leads to serious cracking and coke formation. To decrease the acidity of ZSM-5, TS-1 zeolites with different particle sizes are synthesized and used as a support for Pt-Sn catalysts [20]. The resulting Pt-Sn/TS-1 catalysts exhibit high activity and long-term stability in PDH. Fig. 2 shows the performances of Pt-Sn catalysts supported on TS-1 zeolites with different particle sizes. It can be seen that the TS-1 zeolites with smaller particle sizes that supported Pt-Sn catalysts exhibit higher catalytic performance. For comparison, Pt-Sn catalysts supported on HZSM-5 were synthesized, which reveal really low propylene selectivity and stability, compared to those of Pt-Sn/TS-1 catalysts. This is due to the TS- 1 zeolite with a smaller particle size displaying a hierarchically porous structure, high surface area, and low acidity, which are good for mass transport, Pt-Sn dispersion, and propylene desorption. However, owing to the presence of weak interactions between Pt-Sn and TS-1, the regeneration stability of Pt-Sn/TS-1 catalyst is really low (Fig. 2d).

Over the last several years, some articles have reported a number of Pt/zeolite catalysts that exhibited high performances in PDH. However, the utilization of zeolites as supports of Pt-based catalysts in PDH is still a great challenge owing to their high acidity, which results in side reactions such as cracking and deep dehydrogenation. Furthermore, the weak interaction between Pt and zeolite would lead to the growth of the Pt particles during the PDH process.

Nanocarbons have also been used as supports in the preparation of Pt-based catalysts [69-71]. Volynkin et al. investigated four different nanocarbon (namely, carbon black, carbon nanofibers, carbon nanotubes, and graphite)-supported Pt-based catalysts for the PDH reaction [69]. It was found that Pt nanoparticles supported on carbon black exhibited the highest activity. This is probably due to the presence of different metal-support interactions between $\mathrm{Pt}$ and the carbon supports. Liu et al. reported that $\mathrm{Pt}$ supported on nanodiamond@graphene (ND@G) revealed high catalytic stability for PDH [70]. The presence of strong metal-support interactions can significantly prevent the Pt species from sintering and promote the desorption of propylene. After $100 \mathrm{~h}$ time-on-stream, only a slight loss in the activity can be observed for the Pt/ND@G catalyst. Later, Liu et al. [71] reported a defect-driven Pt/CNTs catalyst for PDH. Owing to the pres- 

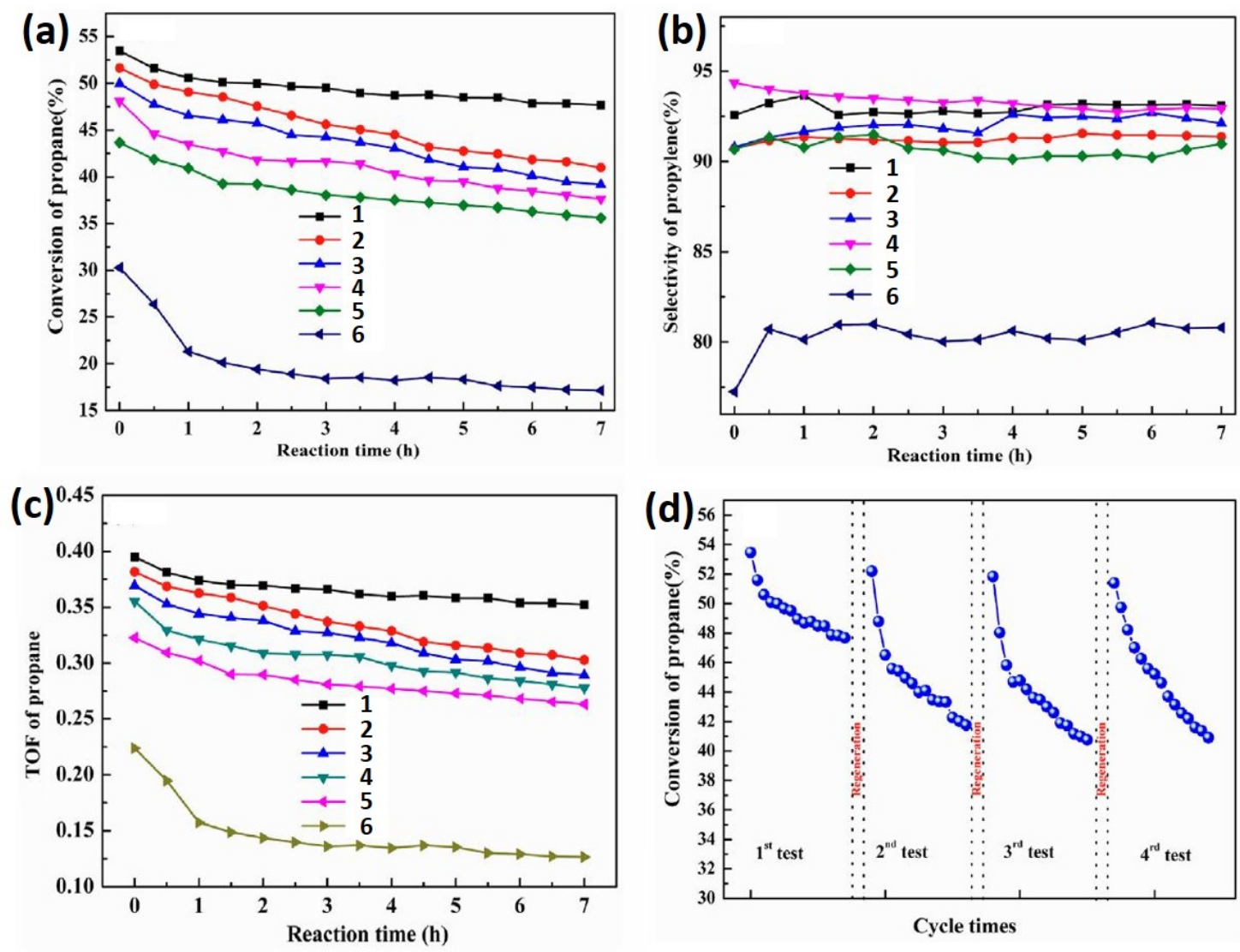

Fig. 2. (a) Propane conversion, (b) propylene selectivity, (c) TOF of propane conversion, and (d) cycle testing of PtSn/TS-1 as functions of reaction time. Note that $x$ represents different crystal sizes: $100 \mathrm{~nm}(1), 201 \mathrm{~nm}(2), 305 \mathrm{~nm}(3), 650 \mathrm{~nm}(4), 1.10 \mu \mathrm{m}(5)$, and $5.72 \mu \mathrm{m}(6)$ [20].

ence of strong interactions between the Pt species and the defects of CNTs, the as-synthesized Pt/CNTs catalyst exhibits high activity, stability, and anti-coking ability in PDH. However, regeneration of this catalyst system is a critical issue that needs to be addressed.

In summary, supports play an important role in determining the performances of Pt-based catalysts in PDH. Generally, a good support for Pt-based catalysts should display a high surface area and good thermal stability. $\mathrm{Al}_{2} \mathrm{O}_{3}$ is a widely used support in Pt-based dehydrogenation catalysts. However, the high acidity of $\mathrm{Al}_{2} \mathrm{O}_{3}$ would result in serious cracking and coke formation. Introducing a non-acidic metal oxide (such as $\mathrm{SiO}_{2}$, $\mathrm{MgO}$, or $\mathrm{TiO}_{2}$ ) into $\mathrm{Al}_{2} \mathrm{O}_{3}$ has been considered as a very promising method of improving the performance of $\mathrm{Pt}-\mathrm{Al}_{2} \mathrm{O}_{3}$-based catalysts, because the introduction of metal oxides can decrease the acidity and increase the stability of Pt catalysts. Furthermore, this method has the advantages of easy operation, low cost, and high efficiency, and can be widely used in the preparation of Pt-based catalysts. Besides, some novel supports (such as zeolites and nanocarbons) have been employed for Pt catalysts. However, the high acidity of zeolites (which results in cracking and low selectivity) and the difficult regenerability of nanocarbons limit their widespread application.

\subsubsection{Effect of promoters on Pt-based catalysts}

Generally, a pure Pt catalyst exhibits a really low perfor- mance in PDH $[51,52]$. In industry, the commercially utilized Pt-based catalysts are based on Pt-Sn $/ \mathrm{Al}_{2} \mathrm{O}_{3}$, rather than on $\mathrm{Pt} / \mathrm{Al}_{2} \mathrm{O}_{3}$. A number of studies have reported that the addition of promoters can greatly improve the dispersion and structural and electronic properties of Pt-based catalysts [19-21,23,54-68], thus improving their activity, selectivity, stability, and anti-coking capability in the PDH process.

Up to now, the widely used promoter is Sn. During the $\mathrm{H}_{2}$ pretreatment process, a Pt-Sn alloy would be formed [72]. Density functional theory (DFT) reveals that propylene would be deeply dehydrogenated on the Pt particles. After the formation of the Pt-Sn alloy, the dehydrogenation barrier of the propylene on the Pt-Sn alloy is much higher than that of the propylene on Pt particles, which results in enhanced selectivity, stability, and anti-coking capability [73]. However, there are many phases present such as $\mathrm{Pt}_{3} \mathrm{Sn}, \mathrm{Pt}_{2} \mathrm{Sn}_{3}, \mathrm{PtSn}$, and $\mathrm{PtSn}_{4}$ in the as-prepared Pt-Sn catalysts. Particularly, the Pt/Sn ratios and the positions of $S n$ would have great influences on the performances of Pt catalysts. Zhu et al. [74] developed a surface organometallic method for the synthesis of Pt-Sn nanoparticles with surface-enriched $\mathrm{Sn}$, which were supported on $\mathrm{MgAl}_{2} \mathrm{O}_{4}$ and used for PDH; these catalysts exhibited high catalytic activity and long-term stability (Fig. 3). This is due to the high concentration of inactive Sn on the surface of the Pt nanoparticles, which results in many isolated active Pt atoms (Fig. 3a-3c). Furthermore, the $\mathrm{Pt} / \mathrm{Sn}$ ratio can greatly influence the activity 

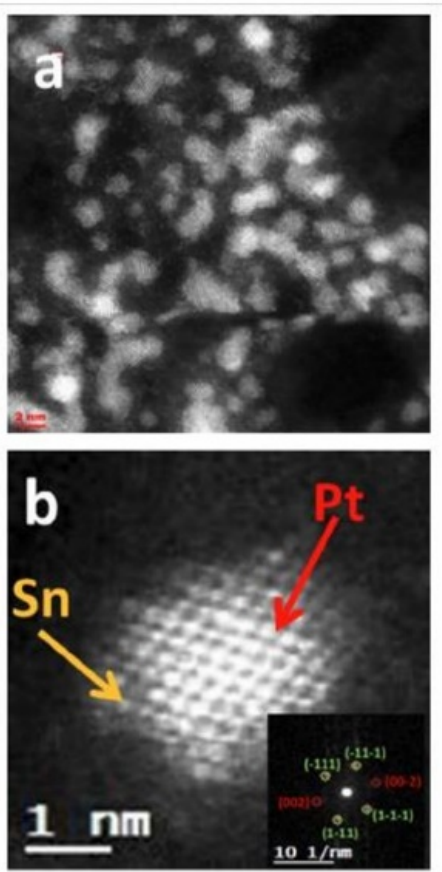
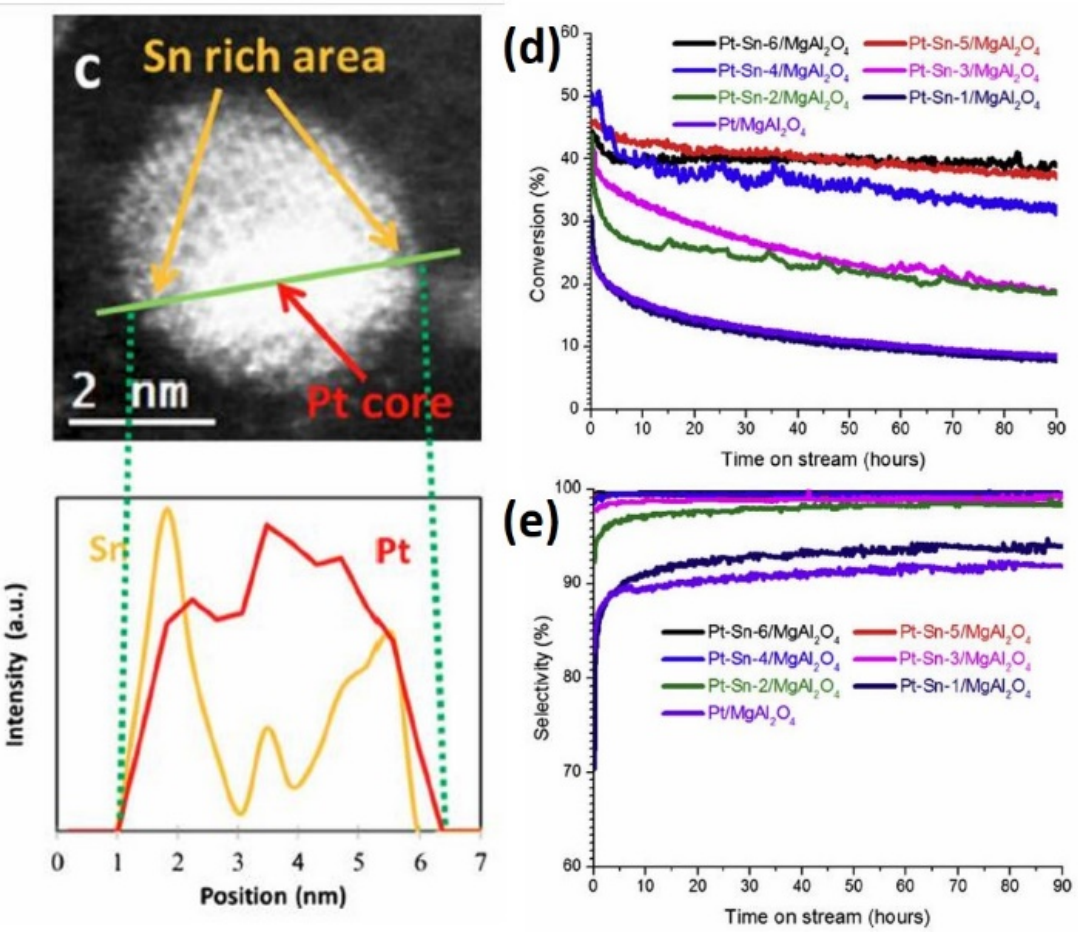

Fig. 3. (a) TEM, (b) HAADF-STEM, and (c) EELS line scans of Pt-Sn particles. (d) Propane conversions and (e) propylene selectivities of different $\mathrm{Pt}-\mathrm{Sn} / \mathrm{MgAl}_{2} \mathrm{O}_{4}$ catalysts [74].

and anti-coking capability of Pt-Sn/MgAl $2 \mathrm{O}_{4}$ catalysts. With increasing $\mathrm{Sn} / \mathrm{Pt}$ ratio from 0 to 2:1, the activity and anti-coking capability of $\mathrm{Pt}-\mathrm{Sn} / \mathrm{MgAl}_{2} \mathrm{O}_{4}$ catalysts increase obviously (Fig. 3d-3e). Another study reported a highly selective and durable Pt-Sn catalyst for PDH, in which the active Pt clusters were confined by the lattice of Sn(IV/II), forming a number of highly stable raft-like Pt clusters [75]. The resulting $\mathrm{Pt} / \mathrm{Mg}(\mathrm{Sn})(\mathrm{Al}) \mathrm{O}$ catalysts exhibit high activity and long-term stability in the PDH reaction. For $240 \mathrm{~h}$ time-on-stream at $550{ }^{\circ} \mathrm{C}$, the conversion decreases at the rate of only $0.0067 \% \mathrm{~h}^{-1}$, which is suggestive of a very promising PDH catalyst. Furthermore, a number of supported Pt-Sn catalysts (such as Pt-Sn/ $\mathrm{Al}_{2} \mathrm{O}_{3}[56,57,76]$, $\mathrm{PtSn} / \mathrm{Al}_{2} \mathrm{O}_{3} / \mathrm{SBA}-15$ [65,66,77], PtSnNa@SUZ-4 [78,79], and $\mathrm{Pt}-\mathrm{Sn} / \mathrm{SiO}_{2}$ [80]) have been synthesized and used in PDH. The utilization of $\mathrm{Sn}$ as a promoter can greatly improve the activity, stability, and anti-coking capability of Pt-based catalysts.

$\mathrm{Zn}$ is another widely used promoter in Pt-based catalysts. After the addition of $\mathrm{Zn}$, the surface, structural, geometric, and electronic properties of Pt catalysts would be greatly changed. Zhang et al. [68] reported that Pt supported on Zn containing ZSM-5 exhibited enhanced catalytic activity and stability in $\mathrm{PDH}$. The addition of Zn can poison the strong acidity of ZSM-5 zeolite and simultaneously improve the dispersion of Pt species, avoiding side reactions (such as cracking, deep dehydrogenation, and coke formation). PtZn alloy would be formed during the $\mathrm{H}_{2}$ pretreatment, which would also be good for improving the catalytic activity and stability [81]. Cybulskis et al. [82] reported that the $\mathrm{Zn}$ species could affect the geometric and electronic properties of the Pt species. It was found that the surface electronic structure and valence orbitals at the active metal sites can be tuned by using Zn promoters. Particularly, the formation of $\mathrm{Pt}_{1} \mathrm{Zn}_{1}$ intermetallic alloy with uniformly isolated Pt surface sites can suppress the rates of structure-sensitive reactions (such as cracking and hydrogenolysis). Furthermore, the addition of Zn can decrease the energy of the filled states of the Pt surface, and weaken the formation of bonds between the $5 \mathrm{~d}$ orbitals and adsorbates. Belskaya et al. [60] reported that the addition of $\mathrm{Zn}$ could affect the structural parameters, textural characteristics, and acid-base properties of the corresponding mixed oxides, which would have great influences on the performances of $\mathrm{Pt} / \mathrm{Mg}(\mathrm{Zn}) \mathrm{AlO}_{x}$ catalysts. The structure and the strength of the interactions between Pt and supports are strongly dependent on the $\mathrm{Zn}$ content. The addition of $\mathrm{Zn}$ can decrease the particle size of the active metal and improve the stability of Pt particles, thereby ensuring high activity and selectivity. Very recently, Chen and coworkers [83] reported that Pt-Zn supported on high-silica HZSM-5 exhibit high catalytic activity and excellent stability in PDH. The framework Zn species in HZSM-5 zeolite can improve the dispersion and stability of Pt particles, and thus, increase the stability of Pt catalysts. On a different note, Gong's group [84] reported that $\mathrm{ZnO}$ is an active site for the $\mathrm{PDH}$ reaction. After doping only a small amount of Pt, the Lewis acid sites of $\mathrm{ZnO}$ would be greatly increased. Thus, the catalytic activity of $\mathrm{ZnO} / \mathrm{Al}_{2} \mathrm{O}_{3}$ can be greatly increased. Indeed, single $\mathrm{Zn}^{2+}$ supported on $\mathrm{SiO}_{2}$ were reported to be active for alkane dehydrogenation [85-87]. Up to now, the active sites of Pt-Zn catalysts for PDH are still debated.

In is reported to be a good promoter for Pt-based catalysts in PDH. Zha et al. [88] compared the catalytic performances of $\mathrm{Pt}, \mathrm{Pt}_{3} \mathrm{In}$, and $\mathrm{Pt}_{3} \mathrm{Sn}$ in PDH by using DFT. It is found that $\mathrm{Pt}_{3} \mathrm{In}$ displays an activity that is comparable to those of $\mathrm{Pt}$ and $\mathrm{Pt}_{3} \mathrm{Sn}$, 
but its selectivity towards propylene is higher than that of Pt. This is due to an apparent increase in electron transfer from In to Pt. Therefore, the adsorption energy of propylene would be moderated after the addition of In. Sun et al. [89] prepared a series of $\mathrm{Pt} / \mathrm{Mg}(\mathrm{In})(\mathrm{Al}) \mathrm{O}$ catalysts for $\mathrm{PDH}$. Upon reduction in $\mathrm{H}_{2}$, PtIn alloy with particle size of $1 \mathrm{~nm}$ would be formed. Furthermore, the content of In in the PtIn alloy increases with increases in the reduction temperature and In/Pt ratio. X-ray absorption near edge structure (XANES) reveals increasing transfer of electronic charges from In to Pt with the increase in the In content, which greatly influences the performance of $\mathrm{Pt} / \mathrm{Mg}(\mathrm{In})(\mathrm{Al}) \mathrm{O}$ catalysts. When the $\mathrm{In} / \mathrm{Pt}$ ratio is 0.48 , $\mathrm{Pt} / \mathrm{Mg}(\mathrm{In})(\mathrm{Al}) \mathrm{O}$ catalyst exhibits the highest activity, with a propylene selectivity of $\sim 100 \%$. Particularly, coke deposition is greatly reduced after the addition of the In species. It is also found that the coke produced on the surface of the PtIn particles can migrate to the support during the PDH process, which ensures high catalytic stability and anti-coking capability. Liu et al. [90] found that the addition of In can decrease the acidity of $\mathrm{PtSn} / \mathrm{Al}_{2} \mathrm{O}_{3}$ catalysts, and thus, decrease cracking and coke formation. Furthermore, metallic In and PtIn alloy would be formed during $\mathrm{H}_{2}$ pretreatment, which can improve the activity and selectivity of Pt-based catalysts. Shen et al. [91] reported that the calcination temperature can affect the performance of PtIn/Mg(Al)O catalysts. After calcination at high temperatures, the flake structure of PtIn/Mg(Al)O catalysts would collapse. A high calcination temperature would lead to the growth of metal particles, which is undesirable for the $\mathrm{PDH}$ reaction.

In addition, $\mathrm{Ga}, \mathrm{Cu}, \mathrm{Mn}, \mathrm{Fe}, \mathrm{Co}, \mathrm{Ni}$, and $\mathrm{Ag}$ have been studied as promoters for improving the performance of Pt-based catalysts in recent years. Copéret's group [19] developed a surface organometallic chemistry method to synthesis nanometric Ga-Pt bimetallic particles that exhibited high activity, selectivity, and stability in PDH. During the preparation process, the Pt precursor $\left[\mathrm{Pt}\left(\mathrm{OSi}(\mathrm{O} t \mathrm{Bu})_{3}\right)_{2}(\mathrm{COD})\right]$ could be grafted onto the surface of $\mathrm{SiO}_{2}$ containing $\mathrm{Ga}$ single sites $\left((\equiv \mathrm{SiO})_{3} \mathrm{Ga}(\mathrm{HOSi} \equiv)\right.$. The XANES patterns reveal that electrons can transfer from the metallic phase of Ga to the Pt $5 \mathrm{~d}$ band. The addition of Ga can greatly modify the electronic structure of the Pt species, and thus, improve the activity, selectivity, and stability of Pt-based catalysts. Gong's group [92] prepared a highly stable $\mathrm{Pt} / \mathrm{Cu}$ single-atom alloy by coimpregnation method with a high $\mathrm{Cu} / \mathrm{Pt}$ ratio (Fig. 4). It was found that the single Pt atoms are highly dispersed on the $\mathrm{Cu}$ nanoparticles, which dramatically enhances the desorption of propylene and prohibits its further dehydrogenation (Fig. 4a-4e). The resulting Pt/Cu catalysts exhibit high PDH stability of more than $120 \mathrm{~h}$ at $520^{\circ} \mathrm{C}$ (Fig. $4 \mathrm{f}$ and $4 \mathrm{~g}$ ). Subsequently, they developed a well-defined Pt-skin catalyst that was modified by using different $3 d$ transition metal atoms. The propylene selectivity was found to follow the order Pt $<$ PtNi@Pt $<$ PtCo@Pt $<$ PtFe@Pt, which was in line with the trend calculated for the shifting of the $d$-band center [93]. Wu et al. [94] reported that the addition of Mn to Pt could change the catalytic and adsorption properties of Pt-based catalysts. When Pt-based catalysts contain a $\mathrm{Pt}_{3} \mathrm{Mn}$ subsurface, they exhibit a higher selectivity towards $\mathrm{C}-\mathrm{H}$ bond activation than towards $\mathrm{C}-\mathrm{C}$ bond activation during the PDH process. The for- mation of $\mathrm{Pt}_{3} \mathrm{Mn}$ phase can significantly reduce the heat of adsorption of the reactant, thus improving the activity and stability of Pt catalysts. Zhang's group [95] investigated the influence of group IB metals $(\mathrm{Cu}, \mathrm{Ag}$, and $\mathrm{Au})$ on $\mathrm{Pt} / \mathrm{MgAl}_{2} \mathrm{O}_{4}$ catalysts. It was found that $\mathrm{Pt}-\mathrm{Cu} / \mathrm{MgAl}_{2} \mathrm{O}_{4}$ catalyst exhibits excellent propane yield and regeneration stability, presumably owing to the formation of intermetallic compounds and little phase segregation during the cyclic dehydrogenation-regeneration runs.

In the PDH process occurring over Pt-based catalysts, a supported pure Pt catalyst usually exhibits low activity and selectivity. After the introduction of promoters (such as Sn, In, $\mathrm{Zn}, \mathrm{Cu}, \mathrm{Mn}$, and $\mathrm{Fe}$ ), the performance of Pt-based catalysts can be significantly increased, owing to the great improvements in the dispersion and structural and electronic properties of the Pt catalysts. Among these promoters, $\mathrm{Sn}, \mathrm{Zn}$, and In are the ones that are widely used for Pt catalysts. Sn and $\mathrm{Zn}$ can hinder side reactions such as isomerization and coke formation during alkane dehydrogenation, whereas In can prevent side reactions by poisoning the Brönsted acid sites; the formation of Pt-In alloy has electronic and geometric effects on the Pt species, which decrease the coke formation. With the development of $\mathrm{Pt}$ catalysts, many other transition metals (such as $\mathrm{Cu}, \mathrm{Ag}$, and $\mathrm{Fe}$ ) have been found to be good promoters for Pt-based catalysts. Particularly, single Pt atom and/or alloy Pt- $M$ atoms $(M=\mathrm{Cu}$, $\mathrm{Ag}$, Fe, etc.) can be synthesized and utilized as catalysts in PDH. These provide great opportunities for the utilization of Pt species at the atomic scale. Owing to the presence of atomic Pt species, these catalysts exhibit the advantages of high stability and anti-coking capability, which make them a type of highly promising industrial PDH catalyst.

\subsection{Vanadium oxide-based catalysts}

Supported vanadium oxides $\left(\mathrm{VO}_{x}\right)$ are reported to be one of the most promising alternative catalysts to Pt- and $\mathrm{CrO}_{x}$-based catalysts in $\mathrm{PDH}$, owing to their low price and high catalytic activity. In fresh $\mathrm{VO}_{x}$-based catalysts, there are many kinds of $\mathrm{V}$ species present, such as $\mathrm{V}^{5+}, \mathrm{V}^{4+}, \mathrm{V}^{3+}$, isolated $\mathrm{V}$, oligomeric $\mathrm{V}^{n+}$, and crystalline $\mathrm{V}_{2} \mathrm{O}_{5}$ [96-104]. Furthermore, $\mathrm{V}^{5+}$ species would be transformed into $\mathrm{V}^{4+}$ and/or $\mathrm{V}^{3+}$ during the PDH process due to the presence of $\mathrm{H}_{2}$.

Generally, the nature of the $\mathrm{V}$ species is strongly dependent on the type of support, $\mathrm{V}$ loading amount, and preparation method. Sokolv et al. [97] reported that the type of support $\left(\mathrm{Al}_{2} \mathrm{O}_{3}, \mathrm{SiO}_{2}(\mathrm{MCM}-41)\right.$, and $\left.\mathrm{Al}_{2} \mathrm{O}_{3}-\mathrm{SiO}_{2}\right)$ can greatly influence the activity and stability of $\mathrm{VO}_{x}$-based catalysts in $\mathrm{PDH} . \mathrm{VO}_{x}$ supported on $\mathrm{Al}_{2} \mathrm{O}_{3}-\mathrm{SiO}_{2}$ with $70 \% \mathrm{SiO}_{2}$ exhibited excellent ability to restore the initial activity, as proven through a series of 10 dehydrogenation/oxidative regeneration cycles. Further, the tendency of the catalyst to form coke increases with the increase in the surface acidity. Later, they pointed out that $\mathrm{VO}_{x}$ species were more active for coke formation than the acid sites of the supports [98]. The rate constant of carbon formation increases with the degree of polymerization of $\mathrm{VO}_{x}$ species. Liu et al. [99] reported that the $\mathrm{V}^{3+}$ in $\mathrm{VO}_{x} / \mathrm{Al}_{2} \mathrm{O}_{3}$ catalysts were the most probable active sites in PDH (Fig. 5). Particularly, the V loading amount can influence the types of $\mathrm{V}$ species present in 

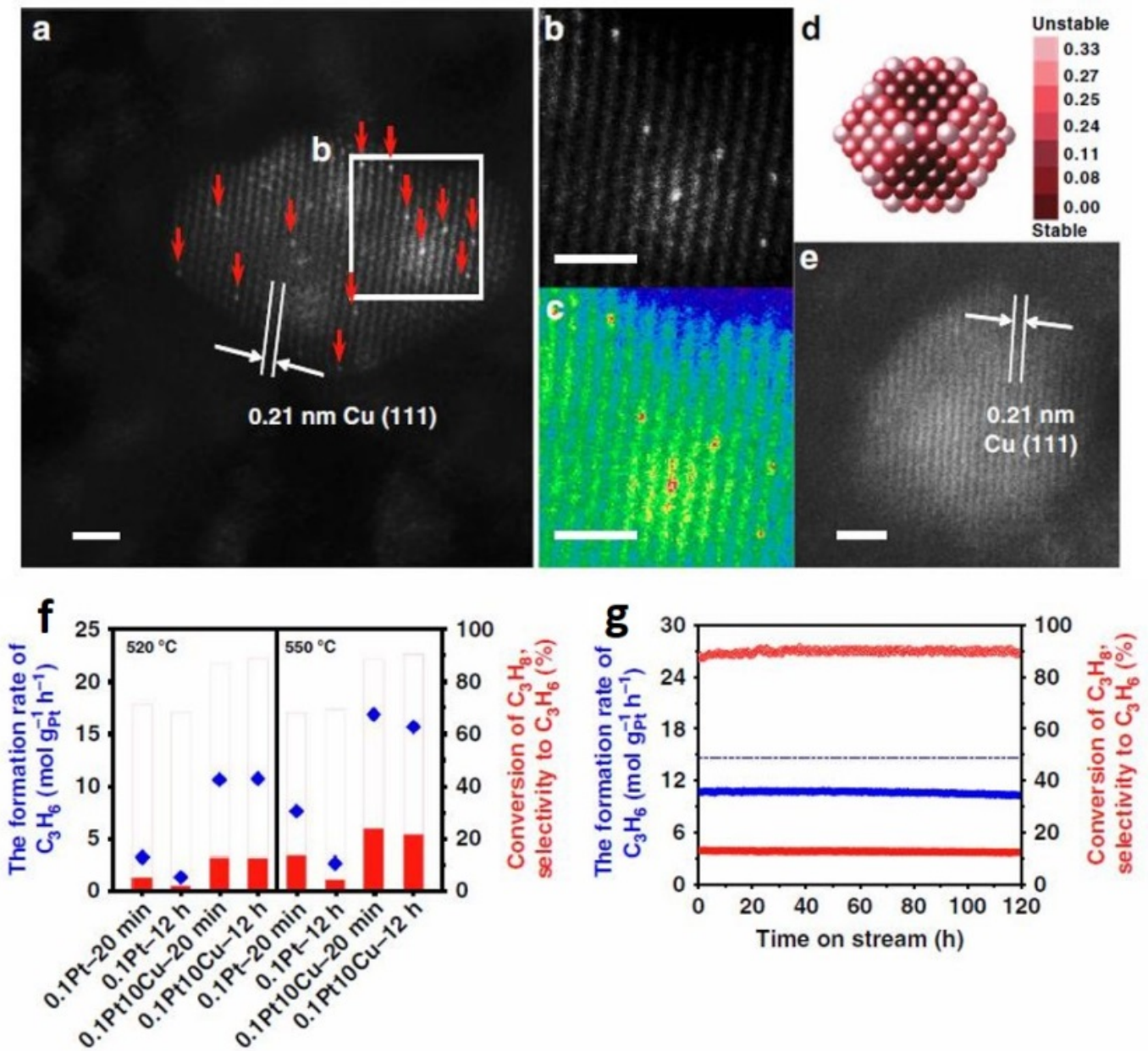

Fig. 4. (a) HAADF-STEM images of reduced $0.1 \mathrm{Pt} 10 \mathrm{Cu} / \mathrm{Al}_{2} \mathrm{O}_{3}$ catalyst. (b, c) Enlarged image and colored intensity map obtained for the region selected in (a). (d) Relative stability of Pt single atoms over $\mathrm{Cu}(\sim 2.1 \mathrm{~nm})$ nanoparticles: dark red indicates a stable location of Pt atom. The unit of the color bar is eV/Pt atom. (e) HAADF-STEM image of a typical region of the reduced $10 \mathrm{Cu} / \mathrm{Al}_{2} \mathrm{O}_{3}$ catalyst, showing no Pt atoms existing on the surface of the $\mathrm{Cu}$ nanoparticles. (f) Catalytic performances at the initial and final stages at $520^{\circ} \mathrm{C}$ and $550^{\circ} \mathrm{C}$ for $12 \mathrm{~h} \mathrm{PDH}$, showing significantly improved performances of $\mathrm{Pt} / \mathrm{Cu}$ single atom alloys, compared with those of Pt nanoparticles. (g) Long-term stability test results of $0.1 \mathrm{Pt} 10 \mathrm{Cu} / \mathrm{Al}_{2} \mathrm{O}_{3}$ at $520{ }^{\circ} \mathrm{C}$ for 120 $\mathrm{h}$. The scale bars correspond to $1 \mathrm{~nm}$ in (a), (b), (c), and (e) [92].

$\mathrm{VO}_{\mathrm{x}} / \mathrm{Al}_{2} \mathrm{O}_{3}$ catalysts. At a low $\mathrm{V}$ loading $(\mathrm{V} / \mathrm{Al}=1.0)$, isolated $\mathrm{V}$ species are mainly dispersed on the $\mathrm{Al}_{2} \mathrm{O}_{3}$ support. With increasing $\mathrm{V}$ loading up to $\mathrm{V} / \mathrm{Al}=1.4$, some polymerized $\mathrm{VO}_{x}$ species would be formed. When the $\mathrm{V}$ loading is higher than $\mathrm{V} / \mathrm{Al}=$ 1.6, crystallite $\mathrm{V}_{2} \mathrm{O}_{5}$ would be formed. Turnover frequency (TOF) result suggests that isolated $\mathrm{V}^{3+}$ species are more active than the other $\mathrm{V}$ sites (such as $\mathrm{V}^{5+}, \mathrm{V}^{4+}$, and $\mathrm{V}_{2} \mathrm{O}_{5}$ ) in the PDH process. In situ diffuse reflectance infrared Fourier transform (DRIFT) spectra (Fig. $5 b$ and $5 c$ ) reveal that $\mathrm{V}-\mathrm{C}_{3} \mathrm{H}_{5}$ is formed during the $\mathrm{PDH}$ process. This indicates that propane activation over the catalyst surface involves the abstraction of a $\mathrm{H}$ atom, and the formed vanadium propyl is then rapidly transformed into $\mathrm{V}-\mathrm{C}_{3} \mathrm{H}_{5}$. Furthermore, the preparation conditions can have a great influence on the performance of $\mathrm{VO}_{x}$ catalysts. Hu et al. [100] reported that the gelation and calcination temperature could greatly influence the structure and performance of $\mathrm{VO}_{x}-\mathrm{SiO}_{2}$ catalysts. At the gelation temperature of $60{ }^{\circ} \mathrm{C}$ and calcination temperature of $580{ }^{\circ} \mathrm{C}$, the obtained $60-\mathrm{VO}_{x}-\mathrm{SiO}_{2}-580$ catalyst exhibits high activity for PDH. How- ever, higher gelation $\left(\geq 75{ }^{\circ} \mathrm{C}\right)$ and calcination temperatures $\left(>580{ }^{\circ} \mathrm{C}\right)$ would result in decreased catalytic performance, owing to the high temperature influencing the structural properties of $\mathrm{VO}_{x}-\mathrm{SiO}_{2}$ catalysts.

Improving the structural properties of $\mathrm{VO}_{x}$-based catalysts is good for mass transport and can provide more accessible active sites. The $\mathrm{VO}_{x}$ species supported on mesoporous $\mathrm{Al}_{2} \mathrm{O}_{3}$ exhibits high catalytic performance in $\mathrm{PDH}$ [101]. Mesoporous $\mathrm{Al}_{2} \mathrm{O}_{3}$ favors the formation of polymerized $\mathrm{VO}_{x}$ species, which are more active than isolated V species in PDH. Alternatively, mesoporous silica can be used as a support for $\mathrm{VO}_{x}$. Rodemerck et al. [102] reported that $\mathrm{VO}_{x}$ species supported on MCM-41 exhibited high catalytic performance in PDH. It was found that isolated $\mathrm{VO}_{x}$ species are more active than their oligomerized counterparts, which is in good agreement with Gong's report [99]. To decrease the acidity of $\mathrm{VO}_{x}$-based catalysts, non-acidic metal oxides are introduced into $\mathrm{VO}_{x}$ catalysts. Wu et al. [103] reported that $\mathrm{MgO}$-modified $\mathrm{VO}_{x} / \mathrm{Al}_{2} \mathrm{O}_{3}$ exhibited enhanced stability, compared with that of pristine $\mathrm{VO}_{x} / \mathrm{Al}_{2} \mathrm{O}_{3}$. This is due 


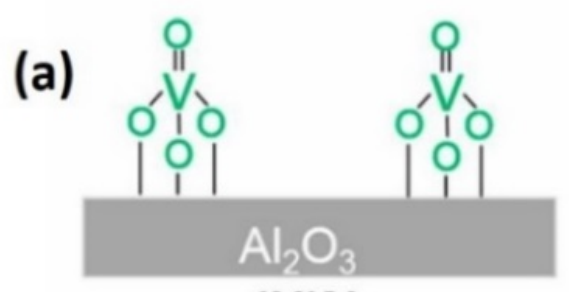

IVIAI

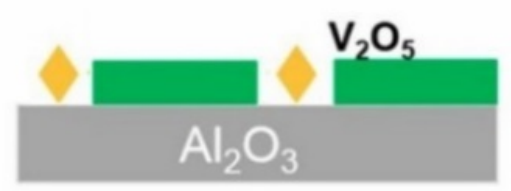

$12 \mathrm{~V} I \mathrm{AI}$

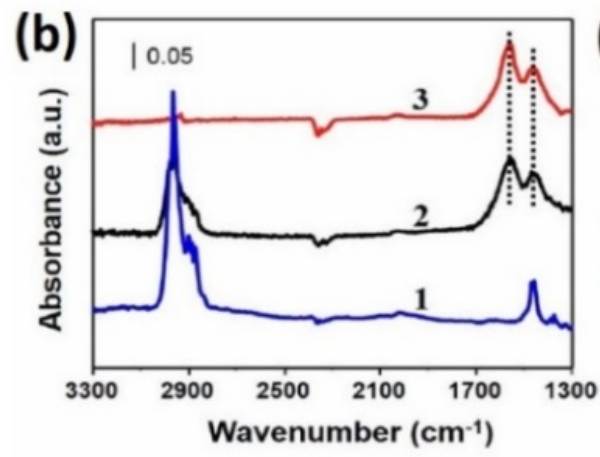

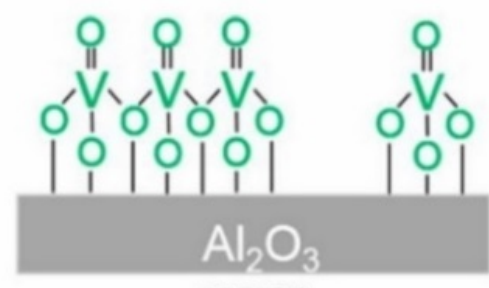

6VIAI

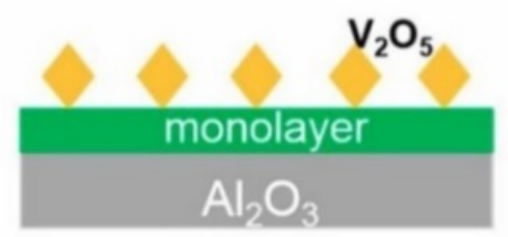

20VIAI

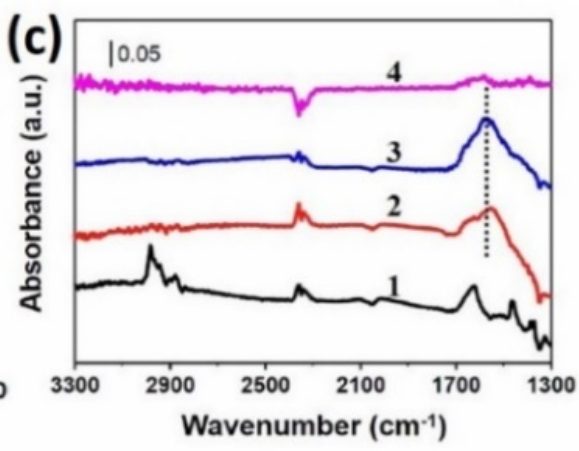

Fig. 5. (a) Proposed surface model of $\mathrm{VO}_{x} / \mathrm{Al}_{2} \mathrm{O}_{3}$ catalyst. (b) DRIFT spectra observed for the reaction of propane over $12 \mathrm{~V} / \mathrm{Al}$ catalyst after (1) propane adsorption at $30^{\circ} \mathrm{C}$, (2) subsequent heating at $300^{\circ} \mathrm{C}$ for $60 \mathrm{~min}$, and (3) evacuation at $30{ }^{\circ} \mathrm{C}$. (c) DRIFT spectra observed after (1) adsorption of propylene at $30{ }^{\circ} \mathrm{C},(2)$ heating at $200{ }^{\circ} \mathrm{C}$ under $\mathrm{H}_{2} / \mathrm{Ar}$ for $30 \mathrm{~min}$, (3) subsequent evacuation at $30{ }^{\circ} \mathrm{C}$, and (4) heating the sample with adsorbed propylene at $200^{\circ} \mathrm{C}$ under He over the $12 \mathrm{~V} / \mathrm{Al}$ catalyst [99].

to the addition of MgO, which improved the dispersion of $\mathrm{V}$ species and decreased the acidity of the catalyst, thereby decreasing the coke formation and improving the stability of $\mathrm{VO}_{x} / \mathrm{Al}_{2} \mathrm{O}_{3}$ catalyst. Furthermore, some methods have been reported for improving the performance of $\mathrm{VO}_{x}$-based catalysts. Zhao et al. [104] proposed a $\mathrm{H}_{2}$ reduction method to increase the amount of hydroxyl species on $\mathrm{VO}_{x} / \mathrm{Al}_{2} \mathrm{O}_{3}$ catalysts. After pretreatment in $\mathrm{H}_{2}$ for only several minutes, the obtained $\mathrm{VO}_{x} / \mathrm{Al}_{2} \mathrm{O}_{3}$ exhibited enhanced catalytic stability in $\mathrm{PDH}$.

Up to now, a number of studies have investigated many efficient $\mathrm{VO}_{x}$-based catalysts. In some cases, their performances are comparable to those of Pt- and $\mathrm{CrO}_{x}$-based catalysts. However, the low stability and bad regenerability of $\mathrm{VO}_{x}$-based catalysts limit their widespread application. Initially, the strong adsorption of propane onto the active sites would lead to coke formation. When the coke is removed by calcination of the catalyst in an oxidizing atmosphere, the $\mathrm{V}$ species tend to aggregate into large crystallite $\mathrm{V}_{2} \mathrm{O}_{5}$ particles, which are inactive in the PDH reaction. Furthermore, there are many $V$ species (such as $\mathrm{V}^{5+}, \mathrm{V}^{4+}, \mathrm{V}^{3+}$, isolated $\mathrm{V}$, oligomeric $\mathrm{V}^{n+}$, and crystalline $\mathrm{V}_{2} \mathrm{O}_{5}$ ) that are present on $\mathrm{VO}_{x}$-based catalysts. The role of each $\mathrm{V}$ species in PDH is still debated.

\subsection{Gallium oxide-based catalysts}

Gallium oxide $\left(\mathrm{GaO}_{x}\right)$-based catalysts have been studied for PDH reaction for years. Particularly, the nature of Ga species is strongly affected by the types of supports, preparation methods, and loading amounts. Zheng et al. [105] reported the presence of many different polymorphs of gallium oxides in supported $\mathrm{GaO}_{x}$ catalysts. Particularly, $\beta-\mathrm{Ga}_{2} \mathrm{O}_{3}$ exhibits the highest activity among all the polymorphs [96]. Shao et al. [106] reported that $\mathrm{GaO}_{x}$ supported on different supports (ZSM-5, SBA-15, $\gamma-\mathrm{Al}_{2} \mathrm{O}_{3}$, and $\mathrm{SiO}_{2}$ ) with different Ga amounts exhibited different catalytic performances in PDH. Catalysis and characterization results reveal that $\mathrm{GaO}_{x}$ supported on ZSM-5 and SBA-15 exhibit high performances owing to the good dispersion of Ga species. By adjusting the Ga loading on SBA-15, it is found that $\mathrm{Ga}_{2} \mathrm{O}_{3} / \mathrm{SBA}-15$ with $5 \mathrm{wt} \% \mathrm{Ga}_{2} \mathrm{O}_{3}$ displays the best catalytic performance owing to its high surface area, well-dispersed $\mathrm{GaO}_{x}$ species, and low acidity. Similarly, Chen et al. [107] found that the $\mathrm{Ga} / \mathrm{Al}$ ratio would affect the acidity properties of spinel-type Gallia-alumina solid solution catalysts ( $\mathrm{Ga}_{x} \mathrm{Al}_{10-x} \mathrm{O}_{15}$ oxides), which influence their catalytic performance in $\mathrm{PDH}$. When $\mathrm{Ga} / \mathrm{Al}$ is $4: 1$, the oxide $\mathrm{Ga}_{8} \mathrm{Al}_{2} \mathrm{O}_{15}$ exhibits the highest catalytic activity. In particular, the formation of spinel-type $\gamma-\mathrm{Ga}_{2} \mathrm{O}_{3}-\mathrm{Al}_{2} \mathrm{O}_{3}$ solid solution plays an important role in the distribution and dispersion of surface Ga species, which renders $\mathrm{Ga}_{\mathrm{x}} \mathrm{Al}_{10-\mathrm{x}} \mathrm{O}_{15}$ composites highly active and stable in 
PDH.

Some novel methods have been explored for improving the performance of Ga catalysts. Searles et al. [108] and Szeto et al. [109] developed a surface organometallic method to synthesize $\mathrm{Ga}-1 / \mathrm{Al}_{2} \mathrm{O}_{3}, \mathrm{Ga}-2 / \mathrm{SiO}_{2}$, and $\mathrm{Ga}-1 / \mathrm{SiO}_{2}$ catalysts (Fig. 6). Through the reaction between the $\mathrm{Ga}$ precursors and $\mathrm{Al}_{2} \mathrm{O}_{3}$, $\mathrm{SiO}_{2}$, and/or Si containing precursors, Ga-based catalysts with single and/or double Ga atoms can be synthesized. The results suggest that the $\mathrm{Al}_{2} \mathrm{O}_{3}$-supported catalyst exhibits promising activity and high selectivity toward propylene. These studies provide a new strategy to synthesize single and/or double Ga atom catalysts.

Additionally, $\mathrm{GaO}_{x}$ species supported on zeolites with MFI structure are widely reported [110-115]. After the Ga species are supported on zeolites, their dispersion, structure, and electronic properties would be greatly improved. Particularly, the types, acidities, and porous structures of zeolites would significantly influence the performance of Ga-zeolite catalysts. Ren et al. [110] reported that the acidity and pore geometry of the support would have a great influence on the performance of $\mathrm{GaO}_{x}$-based catalysts. By adjusting the $\mathrm{Si} / \mathrm{Al}$ ratio of HZM5-48, it is found that the activity of $\mathrm{Ga}_{2} \mathrm{O}_{3} / \mathrm{HZSM}-48$ decreases with increasing $\mathrm{Si} / \mathrm{Al}$ ratio, while the selectivity shows an opposite trend. Furthermore, it is found that the stability of $\mathrm{Ga}_{2} \mathrm{O}_{3} / \mathrm{HZSM}-48$ is lower than that of $\mathrm{Ga}_{2} \mathrm{O}_{3} / \mathrm{HZSM}-5$, which is probably due to the presence of abundant weak acid sites and unidimensional pore structure in HZSM-48. Kim et al. [111] prepared a series of hierarchical Ga-MFI catalysts. It is found that hierarchical Ga-MFI catalysts display greater Lewis acid sites than bulk catalysts, which exhibit better PDH performance. Additionally, Choi et al. [112] prepared a series of gallosilicate MFI zeolites with perturbed acidities, which exhibited high catalytic activity and stability. This is due to the reduced
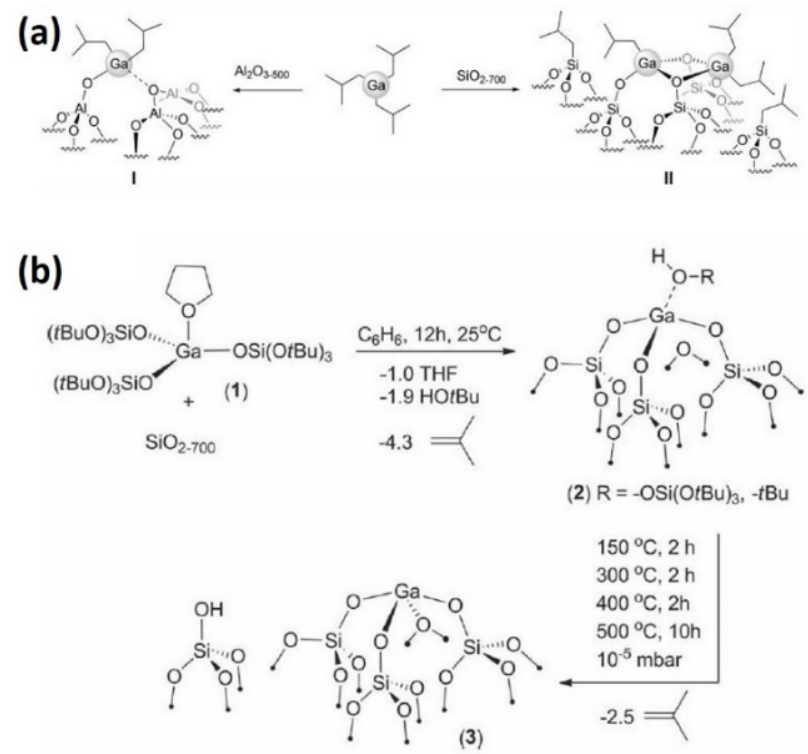

Fig. 6. (a) Grafting of $\mathrm{Ga}(i-\mathrm{Bu})_{3}$ onto $\mathrm{Al}_{2} \mathrm{O}_{3}-500$ and $\mathrm{SiO}_{2}-700$, which lead to structurally distinct surface species. (b) Synthesis of $\left[(\equiv \mathrm{SiO})_{3} \mathrm{Ga}(\mathrm{HOR})\right]\left(2, R=-\mathrm{Si}(\mathrm{O} t \mathrm{Bu})_{3}\right.$ or $\left.-t \mathrm{Bu}\right)$ and its thermal transformation under high vacuum yielding $\left[(\equiv \mathrm{SiO})_{3} \mathrm{Ga}(X \mathrm{OSi} \equiv)\right](3, X=\mathrm{H}$ or 三Si) $[108,109]$
Brönsted acidity and enhanced Lewis acidity of gallosilicate MFI zeolites. Lercher et al. [113] proposed a mechanism for $\mathrm{Ga} / \mathrm{HZSM}-5$ catalysts by which the Lewis-Brönsted acid pairs in Ga/H-ZSM-5 could catalyze the dehydrogenation of propane to propylene. DFT revealed that the high activity is attributed to a bifunctional mechanism that proceeds via heterolytic activation of the propane $\mathrm{C}-\mathrm{H}$ bond, which is followed by monomolecular elimination of $\mathrm{H}_{2}$ and desorption of propene. However, Mansoor et al. [114] remodeled Ga/H-MFI catalysts and found that univalent and divalent gallium hydrides, $\left[\mathrm{GaH}_{2}\right]^{+}$and $[\mathrm{GaH}]^{2+}$, respectively, were more active for alkane dehydrogenation, in comparison to $\mathrm{H}^{+}$and $\mathrm{Ga}^{+}$sites. Particularly, $[\mathrm{GaH}]^{2+}$ are the most probable active sites for alkane dehydrogenation.

Furthermore, $\mathrm{In}_{2} \mathrm{O}_{3}-\mathrm{Ga}_{2} \mathrm{O}_{3}$ mixed oxides [116,117] have been synthesized and used in PDH, for which they exhibit a high catalytic activity. However, the activity and selectivity of $\mathrm{GaO}_{x}$-based catalysts are still too low, compared with those of Pt- and $\mathrm{CrO}_{x}$-based catalysts. Furthermore, $\mathrm{GaO}_{x}$-based catalysts exhibit low stability and bad regenerability due to coke formation and the sintering of $\mathrm{GaO}_{x}$ species during the $\mathrm{PDH}$ reaction, which is similar to $\mathrm{VO}_{x}$-based catalysts. Therefore, frequent regeneration (typically through calcination in air) is needed to recover the performance of $\mathrm{GaO}_{x}$-based catalysts. However, the regeneration process would result in the growth of $\mathrm{GaO}_{x}$ particles, which would lead to irreversible deactivation. Besides, the catalytic mechanism and active sites of Ga species are unclear. Further studies and improvements in $\mathrm{GaO}_{x}$-based catalysts for PDH are therefore required.

\subsection{Nanocarbon catalysts}

Nanocarbons (such as graphene, carbon nanotubes, mesoporous carbons, and activated carbons) are green materials that have drawn much attention owing to their high thermal, mechanical, and electrical properties, which have been studied for decades in adsorption, separation, electrochemistry, and heterogeneous catalysis [5-8,118-124]. In heterogeneous catalysis, nanocarbons impregnated with metal and/or metal oxides are usually used for electrocatalysis [125-128], photocatalysis [129,130], and photoelectrocatalysis [131,132]. For the recovery and recycling of metals, particularly noble metals, these supports can be burned off. Recently, many studies have reported that nanocarbons could be directly used as metal-free catalysts for PDH and exhibit activities comparable to those of noble metal and/or metal oxide catalysts [5-8,133-142]. Table 3 lists the recent studies on nanocarbons for PDH. In general, their catalytic performances are related to their surface functional groups, structural properties, defects, and electronic properties.

Owing to the various morphologies and structures, nanocarbon materials can be modified and/or activated by chemical and/or physical methods. Some heteroatoms (O, P, N, $S$, etc.) are doped into nanocarbon materials [5-8,143-149]. Fig. 7 shows the different $\mathrm{O}, \mathrm{N}$, and $\mathrm{P}$ functional groups that can be introduced into the nanocarbon structures. O-containing groups (such as ketones, carboxylic anhydrides, lactone, carboxylic acid, ether, and phenol) and $\mathrm{P}$-containing groups $(-\mathrm{P}=0$, 
Table 3

Summary of the catalytic data of nanocarbons for PDH reaction.

\begin{tabular}{|c|c|c|c|c|c|c|c|c|c|}
\hline Catalyst & $\begin{array}{c}S_{\text {BET }} \\
\left(\mathrm{m}^{2} / \mathrm{g}\right)\end{array}$ & $\begin{array}{l}\text { Flow rate } \\
(\mathrm{mL} / \mathrm{min})\end{array}$ & Feed composition & $\begin{array}{l}\text { Reaction tem- } \\
\text { perature }\left({ }^{\circ} \mathrm{C}\right)\end{array}$ & $\begin{array}{c}\text { Conversion }^{\mathrm{a}} \\
(\%)\end{array}$ & $\begin{array}{c}\text { Selectivity }{ }^{\mathrm{b}} \\
(\%)\end{array}$ & $\begin{array}{l}\text { Space time } \\
\text { yield }^{c}\left(\mathrm{~h}^{-1}\right)\end{array}$ & $\begin{array}{c}\text { Catalyst life }{ }^{d} \\
\text { (h) }\end{array}$ & Ref. \\
\hline$\overline{\text { OMC-1 }}$ & 624 & 40 & $\mathrm{C}_{3} \mathrm{H}_{8} / \mathrm{N}_{2}=1: 19$ & 600 & $69.3-44.5$ & $62.2-85.1$ & 0.24 & 100 & [133] \\
\hline OMC-2 & 610 & 40 & $\mathrm{C}_{3} \mathrm{H}_{8} / \mathrm{N}_{2}=1: 19$ & 600 & $65.7-39.3$ & $70.6-88.6$ & 0.26 & 100 & [133] \\
\hline HOMC & 675 & 40 & $\mathrm{C}_{3} \mathrm{H}_{8} / \mathrm{N}_{2}=1: 19$ & 600 & $20.1-10.3$ & $66.1-78.5$ & 0.06 & 50 & [135] \\
\hline COMC & 758 & 40 & $\mathrm{C}_{3} \mathrm{H}_{8} / \mathrm{N}_{2}=1: 19$ & 600 & $22.6-12.1$ & $89.0-95.1$ & 0.09 & 50 & [135] \\
\hline ND-1100 & 350 & 15 & $\mathrm{C}_{3} \mathrm{H}_{8} / \mathrm{He}=1: 49$ & 550 & 10.6 & 90 & 0.013 & 15 & [136] \\
\hline MCO & 310 & 40 & $\mathrm{C}_{3} \mathrm{H}_{8} / \mathrm{N}_{2}=1: 19$ & 600 & $32.9-21.2$ & $66.3-86.6$ & 0.12 & 50 & [137] \\
\hline PMC & 679 & 20 & $\mathrm{C}_{3} \mathrm{H}_{8} / \mathrm{N}_{2}=1: 19$ & 600 & 37.1 & 89.2 & 0.19 & 24 & [138] \\
\hline $\mathrm{BMC}$ & 690 & 20 & $\mathrm{C}_{3} \mathrm{H}_{8} / \mathrm{N}_{2}=1: 19$ & 600 & 33.9 & 87.2 & 0.17 & 24 & [138] \\
\hline NMC & 908 & 20 & $\mathrm{C}_{3} \mathrm{H}_{8} / \mathrm{N}_{2}=1: 19$ & 600 & 18.6 & 84.6 & 0.09 & 24 & [138] \\
\hline 1\%P/CMK-3 & 1338 & 20 & $\mathrm{C}_{3} \mathrm{H}_{8} / \mathrm{N}_{2}=1: 19$ & 600 & 28 & 88 & 0.28 & 24 & [139] \\
\hline CMSC-3-700 & 1400 & 20 & $\mathrm{C}_{3} \mathrm{H}_{8} / \mathrm{N}_{2}=1: 19$ & 600 & $41.3-24.7$ & $88.6-93.5$ & 0.21 & 10 & [140] \\
\hline BDAC-700 & 1078 & 20 & $\mathrm{C}_{3} \mathrm{H}_{8} / \mathrm{N}_{2}=1: 19$ & 600 & $54.2-29.7$ & 85.8-91.4 & 0.26 & 50 & [141] \\
\hline so-MWCNTs & 134 & 20 & $\mathrm{C}_{3} \mathrm{H}_{8} / \mathrm{N}_{2}=1: 19$ & 600 & $11.2-5.8$ & $92.1-87.9$ & 0.06 & 4 & [142] \\
\hline
\end{tabular}

a, b The first value is obtained at the start of the cycle, whereas the second is obtained at the end. ${ }^{\mathrm{c}}$ Defined as (weight of propylene formed)/(weight of catalyst $\times t(\mathrm{~h})) .{ }^{\mathrm{d}}$ Total time of a single cycle/experiment.

$-\mathrm{PO}(\mathrm{OH})_{2},-\mathrm{OPO}(\mathrm{OH})_{2}$ and $\left.-\mathrm{P}(\mathrm{OH})_{2}\right)$ can be introduced into the nanocarbons by chemical oxidation [146-148,150-152]. $\mathrm{N}$-containing groups (such as pyridine oxide, amide, amine, pyrrole, pyridine, and lactam) are usually synthesized by carbonization of a $\mathrm{N}$-containing precursor or through reaction with a N-containing reagent [5-8,147-149]. Furthermore, other heteroatoms ( $\mathrm{B}, \mathrm{F}, \mathrm{Cl}$, etc.) can also be introduced into the nanocarbon materials by chemical oxidation and/or carbonization of a heteroatom-containing precursor [5-8]. After nanocarbon materials are doped with heteroatoms, their properties (such as electrical conductivity, porosities, and mechanical and chemical properties) would be significantly improved, which would greatly influence their catalytic performances.

Yuan's group [133] reported that ordered mesoporous carbons (OMCs) exhibited high catalytic activity and long-term stability in PDH. In this study, OMCs (OMC-1 and OMC-2) were prepared by a self-assembly method, where resor-

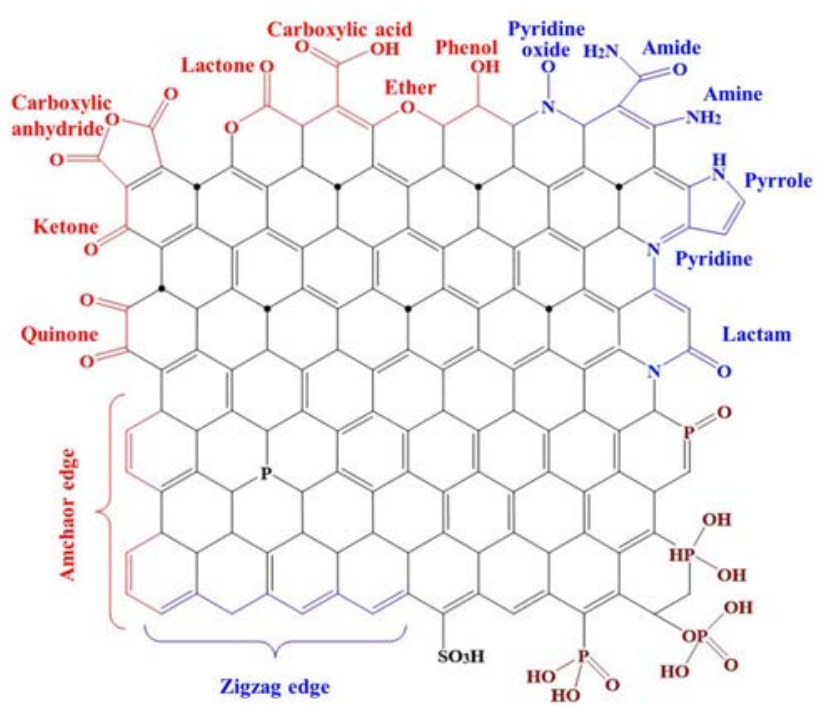

Fig. 7. $\mathrm{O}, \mathrm{N}, \mathrm{P}$, and $\mathrm{S}$ groups with armchair and zig-zag terminations on nanocarbon materials. cinol/formaldehyde precursor and F127 template were mixed with ethanol/water acidic solution in a low-temperature autoclaving condition. The PDH results show that the initial propane conversions of OMC-1 and OMC-2 are $69.3 \%$ and $65.7 \%$, respectively, at the reaction temperature of $600{ }^{\circ} \mathrm{C}$. After $100 \mathrm{~h}$ time-on-stream, the propane conversions of OMC-1 and OMC-2 decrease to $44.5 \%$ and $39.3 \%$, with the propylene selectivities being $85.1 \%$ and $88.6 \%$, respectively (Fig. 8). The stable propylene yield of OMC-1 is about $38 \%$, which is comparable to that of $\mathrm{CrO}_{X^{-}}$and Pt-based catalysts [34,35,38-45,54-58,62-66]. For comparison, CNTs and commercial graphite carbon were tested for PDH, and these exhibited much lower catalytic activities than OMCs. This is probably due to the presence of different porosities. OMCs display high surface area, large pore volume, and uniform pore size, which favor mass transport. Therefore, the produced propylene can easily come out of the mesopores, thereby avoiding subsequent cracking and/or hydrogenolysis. Furthermore, the high surface area of OMCs could supply more active sites for the PDH process. In this catalytic reaction, the carboxyl groups are regarded as the active sites. However, no direct quantification and/or theoretical simulation has revealed the actual active sites. Later, Hu et al. [134] synthesized a series of mesoporous carbons with different pore orders and surface properties for PDH. It
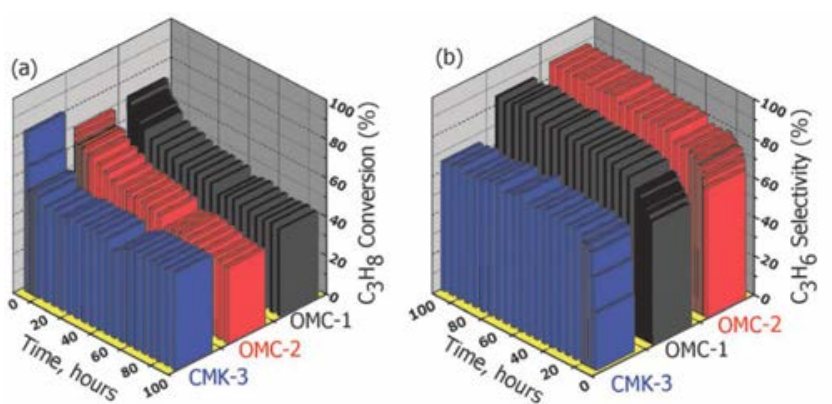

Fig. 8. (a) Propane conversion and (b) propylene selectivity over different OMCs [133]. 
was found that the highly ordered mesoporous carbons exhibit higher catalytic activities than disordered and ordered mesoporous carbons, which further reveal that pore ordering plays a crucial role in determining mass transport and the amounts of accessible active sites.

Monolithic mesoporous carbons (COMC) were prepared via an autoclaving method by using citric acid as the catalyst instead of $\mathrm{HCl}$ [135]. During this preparation process, citric acid played a key role in determining the channel ordering of the obtained OMCs, because the - $\mathrm{COOH}$ groups in the acid could significantly improve the interactions between F127 template and resorcinol/formaldehyde precursor. After carbonization, COMC with a uniform pore size of $\sim 5 \mathrm{~nm}$ and a high specific surface area of $758 \mathrm{~m}^{2} \mathrm{~g}^{-1}$ would be formed. The resultant COMC was used for PDH, and exhibited high catalytic performance and long-term stability. The initial propane conversion and selectivity of COMC are $22.6 \%$ and $89.0 \%$, respectively, which are slightly higher than those of HOMC (prepared by using $\mathrm{HCl}$ ). This study further illustrates that OMCs prepared by various methods can be used for PDH.

In PDH reaction, the catalytic performances of nanocarbon materials are related to their oxygenated functional groups. Therefore, improvement of the surface oxygenated functional groups is an efficient method to increase the catalytic activities of nanocarbon materials. Through $\mathrm{HNO}_{3}$ oxidation, the surface functional groups of OMCs can be increased [137]. The resulting $\mathrm{HNO}_{3}$-activated OMCs exhibit improved catalytic activity, compared with that of pristine OMCs, for PDH. Inevitably, the activation process also results in many acidic functional groups (such as carboxylic acid groups) on the surface of OMCs, which would lead to deep dehydrogenation and cracking.

Heteroatom-doped OMCs were prepared and used for PDH. Song et al. [138] prepared a series of heteroatom (N, P, and B)-doped OMCs (NMC, PMC, and BMC) for PDH. PMC and BMC exhibited improved catalytic activities, compared with those of undoped OMCs, whereas NMC showed a lower catalytic activity. Characterizations suggest that the amounts of the $\mathrm{C}=0$ groups of nanocarbons play a key role in $\mathrm{PDH}$. Doping with $\mathrm{P}$ and $\mathrm{B}$ can increase the number of $\mathrm{C}=0$ groups in nanocarbons, however, $\mathrm{N}$ doping decreases the number of $\mathrm{C}=\mathrm{O}$ groups of nanocarbons. Therefore, the choice of heteroatoms is very important for the preparation of doped nanocarbons for dehydrogenation reactions. Liu and coworkers [139] prepared a series of P-doped CMK-3, which exhibited enhanced catalytic performance in $\mathrm{PDH}$. It was revealed that the $\mathrm{P}=0$ functional groups are additional possible active sites for PDH. However, no further study was carried out to verify this conclusion.

Although OMCs exhibit high catalytic performances in PDH, their preparation is so complex, time-consuming, and expensive that they are unfavorable for commercial utilization. The development of nanocarbons displaying high catalytic performances (activity, selectivity, and stability) at significantly low costs by using an environmental-friendly method for $\mathrm{PDH}$ is very urgent and necessary. Hu et al. $[140,141]$ proposed the utilization of biomass-derived nanocarbons for PDH. Typically, porous carbons with micro/meso/macropores and numerous oxygenated functional groups were prepared by a simple alkali activation method, in which the castanea mollissima shells were calcined with $\mathrm{KOH}$ at a high temperature [140]. During the $\mathrm{KOH}$ activation process, many pores would be introduced into the castanea mollissima shell-derived carbons (CMSCs). The CMSCs were used as metal-free catalysts for PDH, and exhibited high activity, selectivity, and stability. It is notable that the calcination temperature and $\mathrm{KOH} / \mathrm{C}$ ratios corresponding to the activation conditions can significantly affect the catalytic performance of CMSCs. At low calcination temperatures $[<600$ ${ }^{\circ} \mathrm{C}$ ), $\mathrm{KOH}$ cannot activate the $\mathrm{C}$ materials, therefore, only a small number of pores can be introduced into the CMSCs. When the activation temperature is higher than $700{ }^{\circ} \mathrm{C}$, a large number of oxygenated functional groups (active sites) of CMSCs would be decomposed, which results in lower catalytic performances. Therefore, $700{ }^{\circ} \mathrm{C}$ is the suitable activation temperature.

On the basis of the abovementioned studies, it can be concluded that the surface oxygenated functional groups of carbon materials play a key role in $\mathrm{PDH}$. However, there are many kinds of O-containing groups (such as $-\mathrm{OH},-\mathrm{COOH}, \mathrm{C}-\mathrm{O}-\mathrm{C}$, and $\mathrm{C}=0$ groups) in nanocarbon materials. Which kind of functional group is the active site in PDH? Hu et al. [142] developed a sequential oxidation method for the preparation of oxidized MWCNTs. The concentrations and types of the 0-containing groups on MWCNTs can be well controlled by sequential acidic oxidation and thermal treatment, as evidenced by TPD-MS and XPS techniques (Fig. 9a-9c). Then, the obtained MWCNTs are used as metal-free catalysts for PDH. It is found that the activities (propylene formation rates) of these nanocarbons show a good linear dependence on the number of carbonyl/quinone groups, which confirms that the $\mathrm{C}=0$ groups are the active sites (Fig. $9 \mathrm{~d}$ and $9 \mathrm{e}$ ). $\mathrm{C}=\mathrm{O}$ groups are basic groups that can activate propane as the electron donor. Then, propylene and hydroxyl groups $(\mathrm{C}-\mathrm{OH})$ would be formed as the target product and intermediate, respectively. The reaction cycle is completed by the thermal decomposition of the $\mathrm{C}-\mathrm{OH}$ groups to molecular $\mathrm{H}_{2}$ and $\mathrm{C}=\mathrm{O}$ groups.

As metal-free catalysts for PDH, nanocarbons display many advantages such as high stability, non-toxicity, and low cost, which make them a very promising alternative to metal and metal oxide catalysts. The performances of C-based catalysts are strongly affected by their structural and surface properties such as microstructure and surface oxygenated functional groups. The size, shape, and porosity of carbocatalysts can affect the accessibility of the active sites for PDH. The surface oxygenated functional groups, particularly $\mathrm{C}=\mathrm{O}$ groups, are regarded as the active sites in $\mathrm{PDH}$. Therefore, a good C-based PDH catalyst should exhibit a high surface area, be rich in $\mathrm{C}=0$ groups, and offer high stability. Owing to the high performance of carbocatalysts in PDH, many good results have been obtained in this area. However, the regeneration of deactivated carbocatalysts is a great challenge, owing to the fact that $\mathrm{C}$ materials would be burned off in an oxidizing atmosphere.

\subsection{Other catalysts}

Besides the Pt-, $\mathrm{CrO}_{x^{-}}, \mathrm{VO}_{x^{-}}, \mathrm{GaO}_{x^{-}}$-based catalysts, and nanocarbons, some other metal and/or metal oxides (such as 

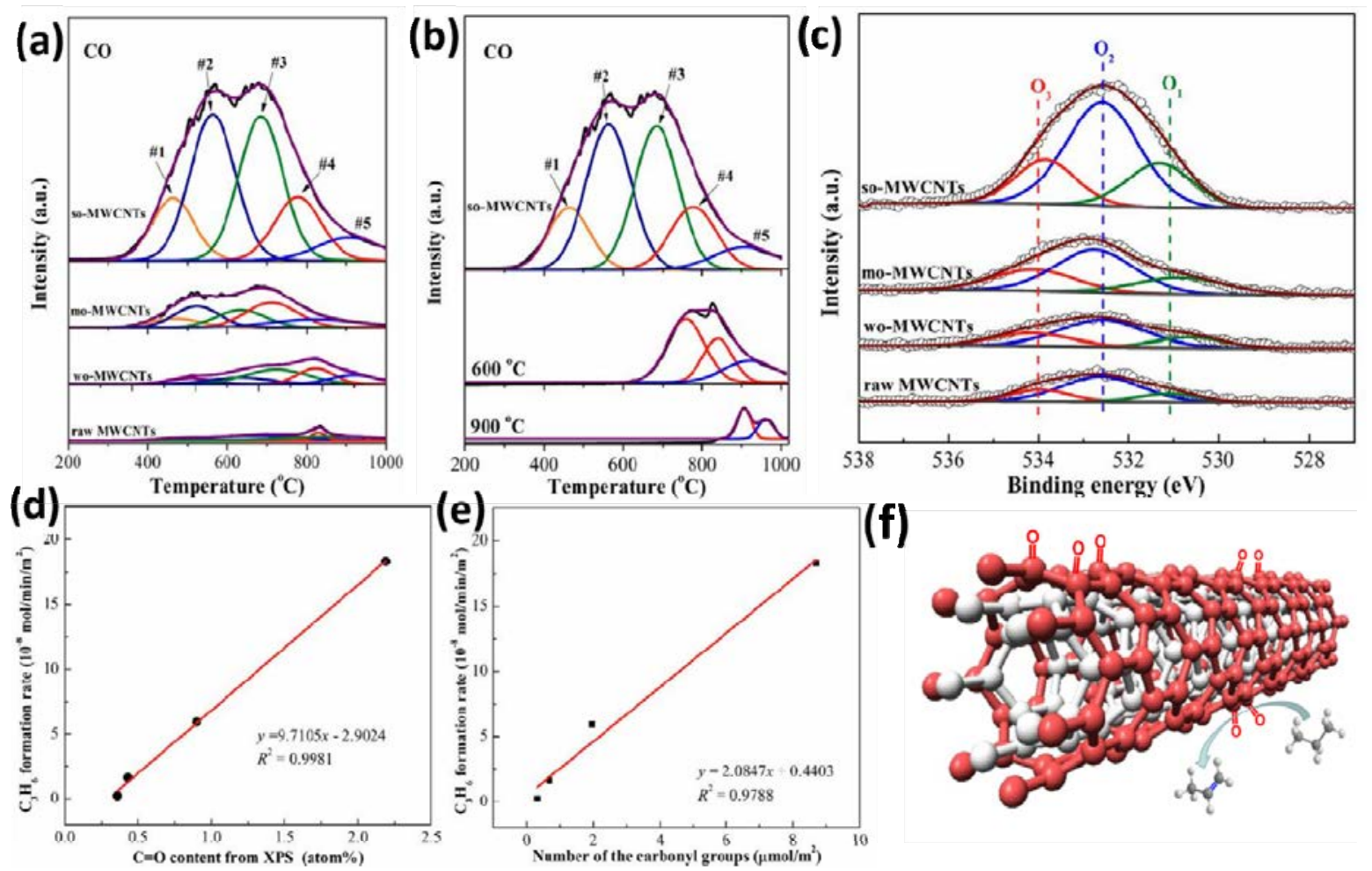

Fig. 9. TPD-MS curves of (a) oxidized MWCNTs and (b) thermally treated so-MWCNTs. (c) $01 s$ XPS spectra of raw oxidized MWCNTs. (d) Initial propylene formation rates of oxidized MWCNTs as functions of number of carbonyl groups, calculated from XPS analysis, and (e) TPD-MS results. (f) Schematic illustration of the PDH process on MWCNTs [142].

$\mathrm{FeO}_{x}, \mathrm{CoO}_{x}, \mathrm{SnO}_{x}, \mathrm{ZnO}_{x}$, and $\mathrm{ZrO}_{2}$-based catalysts) have been studied as catalysts for PDH reaction, which exhibited comparable and/or higher performances than $\mathrm{CrO}_{x^{-}}$and Pt-based catalysts.

Supported Fe catalysts have been found to be active for PDH [150-155]. Sun et al. [150] reported that the $\mathrm{FeO}_{x}$ species supported on sulfated alumina was active for PDH. At $560{ }^{\circ} \mathrm{C}, 20 \%$ propylene yield can be obtained over $20 \mathrm{Fe} / 5 \mathrm{~S}$-Al catalyst. It is revealed that $\mathrm{Fe}-\mathrm{O}-\mathrm{S}$ is formed in $\mathrm{Fe} / \mathrm{S}-\mathrm{Al}$ catalysts, which results in enhanced acidity and activity. Later, they found that by using $\mathrm{Fe}^{2+}$ or $\mathrm{Fe}^{3+}$ sulfate as the precursor, pretreating with $\mathrm{SO}_{2}$, and introducing $\mathrm{SO}_{2}$ with propane as a reactant can affect the performance of $\mathrm{Fe}_{2} \mathrm{O}_{3} / \gamma-\mathrm{Al}_{2} \mathrm{O}_{3}$ catalysts [151]. Particularly, the sulfate species introduced can react with $\gamma-\mathrm{Al}_{2} \mathrm{O}_{3}$ support and Fe species (forming Al-O-S and $\mathrm{Fe}-\mathrm{O}-\mathrm{S}$ ), which are beneficial for the PDH process. Recently, they reported that pre-reduced $\mathrm{Fe}_{2} \mathrm{O}_{3} / \mathrm{Al}_{2} \mathrm{O}_{3}$ exhibited a high catalytic performance in PDH [152]. During the pre-reduction process, $\mathrm{Fe}^{3+}$ would be transformed into $\mathrm{Fe}^{2+}$ and $\mathrm{Fe}$ species, which are considered to be the active sites for PDH. However, the catalytic mechanism and active sites of Fe-based catalysts are still unclear. Additionally, Yun et al. [153] prepared a series of Fe-silicate zeolites, namely [Fe]ZSM-5 samples with Si/Fe ratios of 26 and 48, and [Fe]beta catalyst with $\mathrm{Si} / \mathrm{Fe}$ ratio of 15 . It was found that the Fe-silicate zeolites exhibited much higher dehydrogenation rates than [Fe]H-[Al]ZSM-5. The redox catalytic cycle suggested that propane radical cations would be formed over the isolated $\mathrm{Fe}$ framework sites in [Fe] zeolites during the PDH process. Hu et al. [154] developed a $\mathrm{Fe}^{2+} / \mathrm{SiO}_{2}$ catalyst with isolated $\mathrm{Fe}^{2+}$ spe- cies for PDH. By comparing with those of iron oxide particles and metallic nanoparticles on $\mathrm{SiO}_{2}$, it was found that the isolated $\mathrm{Fe}^{2+} / \mathrm{SiO}_{2}$ catalyst exhibits a much higher propylene selectivity. In situ XANES results reveal that the active sites involve the $\mathrm{Fe}^{2+}$ species. Tan et al. [155] reported that the addition of $\mathrm{P}$ could improve the activity of $\mathrm{Fe} / \mathrm{Al}_{2} \mathrm{O}_{3}$ catalyst. Particularly, $\mathrm{Fe} / \mathrm{P} / \mathrm{Al}$ catalysts with $\mathrm{Fe}: \mathrm{P}$ ratio of 3:1 exhibited the highest activity (propane conversion of $15 \%$, propylene selectivity > 80\%). However, their catalytic activities are really low. In particular, the active sites and catalytic mechanisms are still unclear.

Co-based catalysts are reported to be active for PDH [156-160]. Hu et al. [156] reported that single-site $\mathrm{Co}^{2+}$ on $\mathrm{SiO}_{2}$ were active for $\mathrm{PDH}$. Tetrahedrally coordinated $\mathrm{Co}^{2+}$ species are highly stabilized on the surface of amorphous silica after pretreatment in $\mathrm{H}_{2}$ at $650{ }^{\circ} \mathrm{C}$. During the $\mathrm{PDH}$ process, this catalyst exhibits high propylene selectivities of over $95 \%$ and $90 \%$ at the reaction temperatures of 550 and $650{ }^{\circ} \mathrm{C}$, respectively. DFT further indicates that the $\mathrm{C}-\mathrm{H}$ bond cleavage occurs across a Co- $\mathrm{O}_{\text {support }}$ bond. Mesoporous $\mathrm{CoAl}_{2} \mathrm{O}_{4}$ spinel was also prepared for PDH [157]. The resultant Co-Al catalysts exhibit a high propane conversion of $39 \%$, with a propylene selectivity of over $80 \%$. In this catalyst system, the tetrahedral $\mathrm{Co}^{2+}$ species is regarded as the active sites, which are Lewis sites and experience no significant change in the coordination environment and oxidation state during the PDH reaction. Furthermore, another metal species was introduced into the Co-based catalysts. Zhao et al. [158] prepared a modified $\mathrm{SiO}_{2}$ support with isolated $\mathrm{Zr}$ atoms for supporting $\mathrm{Co}^{2+}$. The as-synthesized 
$\mathrm{Co}-\mathrm{Zr} / \mathrm{SiO}_{2}$ catalyst exhibited higher activity and selectivity than $\mathrm{Co} / \mathrm{SiO}_{2}$ catalyst, due to a change in the $\mathrm{O}$ donating ability and $\mathrm{Co}-\mathrm{O}$ bond strength of the $\equiv \mathrm{SiO}-\mathrm{Zr}-\mathrm{O}$ sites of $\mathrm{Co}-\mathrm{Zr} / \mathrm{SiO}_{2}$. In addition, the states of Co could affect the performance of $\mathrm{Co} / \mathrm{Al}_{2} \mathrm{O}_{3}$ catalyst. After post-treatment of the $\mathrm{Co} / \mathrm{Al}_{2} \mathrm{O}_{3}$ catalysts by using different protocols, they revealed different performances in PDH [159]. Particularly, poor dispersion of Co leads to coking and pyrolysis, while highly dispersed Co species can result in high PDH performances. Furthermore, the addition of sulfate species can affect the performance of $\mathrm{Co} / \mathrm{Al}_{2} \mathrm{O}_{3}$ catalyst in PDH. Sun et al. [160] found that the addition of sulfate could improve the dispersion of Co and restrained the reduction of Co ions to metallic Co species, thereby improving the activity and selectivity of Co-based catalysts. The use of Co-based catalysts for PDH has been rarely reported before. The active sites and catalytic mechanisms are still unclear. Generally, single site and/or isolated $\mathrm{Co}^{2+}$ species are regarded as the active sites in PDH. Furthermore, the activity and selectivity are much lower than those of Pt- and $\mathrm{CrO}_{x}$-based catalysts.

Sn is considered as a promoter for Pt-based catalysts, owing to the formation of Pt-Sn alloy. Wang and coworkers [161,162] reported that $\mathrm{Sn}$ supported on $\mathrm{SiO}_{2}$ exhibited high activity, selectivity and excellent stability in PDH (Fig. 10a-10c). After introduction of a small amount of $\mathrm{Pd}$, the stability of $\mathrm{SnPd} / \mathrm{SiO}_{2}$ catalyst can be enhanced to over $168 \mathrm{~h}$, which is representative of a very promising PDH catalyst. Similarly, Sn-containing hexagonal mesoporous silica (HMS) exhibits a high propane conversion of $\sim 40 \%$ and excellent stability over $170 \mathrm{~h}$ (Fig. 10d). It is revealed that the high stability of $\mathrm{Sn}$-based catalysts is attributed to the formation of strong $\mathrm{Sn}-\mathrm{O}-\mathrm{Si}$ bonds. However, the active sites and mechanism of Sn-based catalysts have not been understood well. More detailed and theoretical studies on
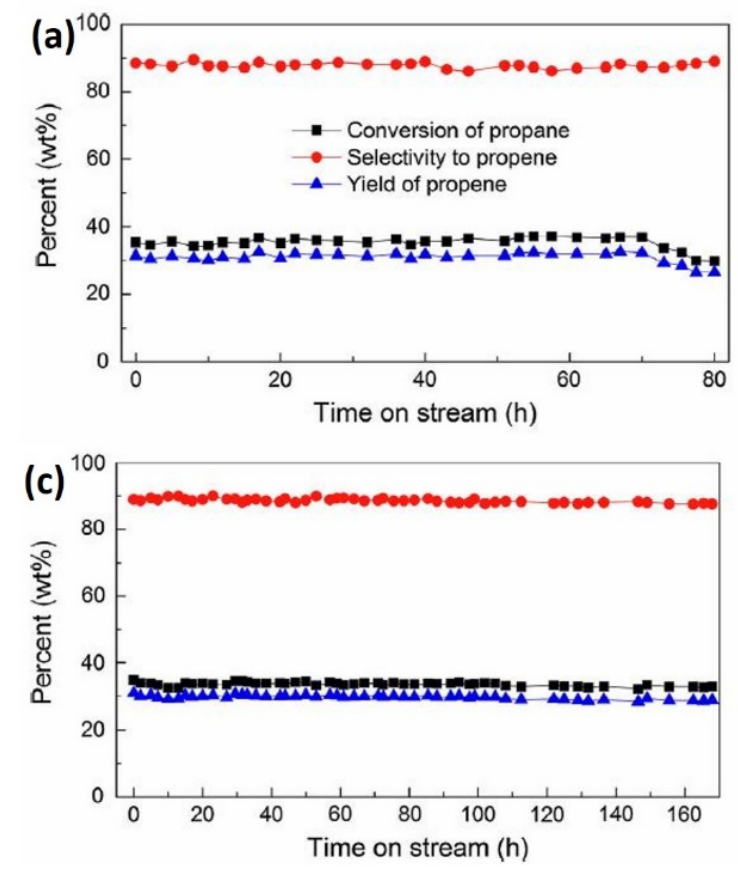

this kind of catalyst are highly desired.

Supported Zn oxides are also reported to be active for PDH [84-87,163]. Schweitzer et al. [85] developed a strong electrostatic adsorption methodology to synthesize $\mathrm{SiO}_{2}$-supported single site $\mathrm{Zn}^{2+}$ catalysts. It is revealed that the $\mathrm{Zn}^{2+}$ are chemisorbed into the strained three-membered siloxane rings present on the amorphous $\mathrm{SiO}_{2}$ surface. During the $\mathrm{PDH}$ reaction, $\mathrm{Zn}^{2+}$ loses one $\mathrm{Zn}-\mathrm{O}$ bond, resulting in a coordinatively unsaturated three-coordinate active center. DFT further reveals that the $\mathrm{C}-\mathrm{H}$ bonds are activated by a non-redox mechanism. Gong et al. [86] reported that ZnO supported on ZSM-5 and Y zeolites exhibited high catalytic performances in PDH. However, the high acidity of zeolites results in serious cracking and coke formation. Camacho-Bunquin et al. [87] prepared a series of $\mathrm{Zn} / \mathrm{SiO}_{2}$ catalysts by using an integrated atomic layer deposition-catalysis instrument. It is found that the catalytic activity of open shell 16-electron, tri-coordinate ethyl Zn-silica sites is much higher than that of 18-electron, tetra-coordinate ZnO-type centers. Furthermore, the loading amount of $\mathrm{Zn}$ can affect the performance of $\mathrm{Zn} / \mathrm{SiO}_{2}$ catalysts. When the $\mathrm{SiO}_{2}$ surface is saturated with $\mathrm{Zn}^{2+}$ sites, a higher $\mathrm{Zn}$ loading would result in $\mathrm{Zn}$ agglomeration and catalyst deactivation. Very recently, Chen et al. [163] reported that ZnO supported on dealuminated beta zeolite exhibited high catalytic activity and long-term stability. This is ascribed to the zeolite structure, which can provide a special environment for stabilizing $\mathrm{Zn}$ species.

Furthermore, $\mathrm{ZrO}_{2}$ has been studied for the $\mathrm{PDH}$ reaction [164-167]. Otroshchenko et al. [164] reported that $\mathrm{ZrO}_{2}$ promoted with other metal oxides exhibited a high activity for PDH. After addition of $0.05 \% \quad \mathrm{Cu}$ and $\mathrm{La}_{2} \mathrm{O}_{3}$ oxides, $\mathrm{Cu} / \mathrm{ZrO}_{2}-\mathrm{La}_{2} \mathrm{O}_{3}$ exhibited industrially relevant activity and durability in $\mathrm{PDH}$. On the other hand, $\mathrm{La}_{2} \mathrm{O}_{3}-\mathrm{ZrO}_{2}$ and $\mathrm{Y}_{2} \mathrm{O}_{3}-\mathrm{ZrO}_{2}$
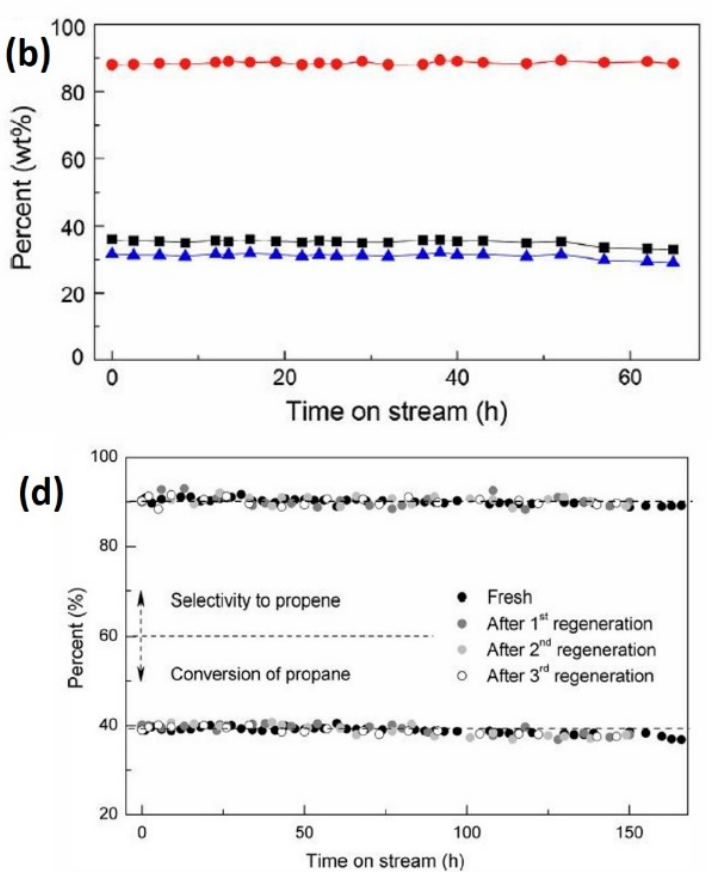

Fig. 10. Catalytic performances of propane dehydrogenation over (a) fresh $\mathrm{Sn} / \mathrm{SiO}_{2}$, (b) regenerated $\mathrm{Sn} / \mathrm{SiO}{ }_{2}$, (c) $\mathrm{SnPd} / \mathrm{SiO}{ }_{2}$, and (d) $\mathrm{Sn}-\mathrm{HMS}$ catalysts $[161,162]$. 
displayed PDH activities that were comparable to that of conventional $\mathrm{K}-\mathrm{CrO}_{x} / \mathrm{Al}_{2} \mathrm{O}_{3}$ catalyst [165]. The coordinatively unsaturated $\mathrm{Zr}$ cations and neighboring lattice $\mathrm{O}$ are responsible for the $\mathrm{C}-\mathrm{H}$ cleavage occurring during the PDH. Zhang et al. [166] revealed through quantum chemical calculations that $\mathrm{ZrO}_{2}$ with coordinatively unsaturated $\mathrm{Zr}$ sites was active for $\mathrm{C}-\mathrm{H}$ bond dissociation. Particularly, the crystallite size of $\mathrm{ZrO}_{2}$ can affect the concentration of anion vacancies in $\mathrm{ZrO}_{2}$, and thus, affect the PDH performance.

In summary, the performances of supported transition metal catalysts (such as $\mathrm{FeO}_{\mathrm{x}}, \mathrm{CoO}_{\mathrm{x}}, \mathrm{SnO}_{\mathrm{x}}, \mathrm{ZnO}_{\mathrm{x}}$, and $\mathrm{ZrO}_{2}$-based catalysts) in PDH reaction are strongly affected by the preparation methods, type of supports, and nature of active sites. The preparation methods can affect the properties (such as shape, size, and distribution) of the catalysts. The type of supports can affect the stability, states, and electronic properties of the active sites, and thus, affect the catalytic performances. Usually, isolated and/or unsaturated metal species are regarded as the active sites for PDH. However, they exhibit low stability and tend to aggregate into large particles, resulting in low stability and regenerability. Therefore, the development of novel methods and supports for stabilizing these transition metal species is of great significance. Over the last several years, great efforts have been made to improve the stability of transition metal catalysts in PDH. Particularly, surface organometallic method is a very promising method of synthesis of highly stable PDH catalysts with isolated metal active sites $[157,159,161]$. Owing to the well-defined structure of the metal species, the catalytic mechanisms and active sites of these catalysts can be identified.

\section{Summary and outlook}

With growing demand for propylene and increasing production of propane from shale gas, direct PDH has drawn particular attention and has been regarded as one of the most promising methods of propylene production. In particular, many new PDH projects have been announced and established in recent years. Up to now, the two widely used crafts are Catofin ( $\mathrm{CrO}_{x}$-based catalysts) and Oleflex (Pt-based catalysts) technologies. These two catalyst systems display many advantages such as high activity and selectivity. However, a few drawbacks (such as cracking, deep dehydrogenation, and coke formation) limit their applications. Over the last several years, great efforts have been made to improve the performances of $\mathrm{CrO}_{x}$ - and Pt-based catalysts by using various strategies, such as using different supports, improving the structural properties, introducing promoters, and/or developing new preparation methods. Although some improvements have been achieved, the stabilities of $\mathrm{CrO}_{x^{-}}$and Pt-based catalysts are still too low. Therefore, frequent regeneration is required to remove the coke and recover the catalytic activity. For Pt-based catalysts, their stability is slightly higher than that of $\mathrm{CrO}_{x}$-based catalysts. However, coke formation and sintering of Pt nanoparticles are two key factors affecting the performance of Pt-based catalysts. Recent studies on Pt-based catalysts have focused on the exploitation of single atom Pt and/or Pt-M alloys (where M represents a metal species, such as $\mathrm{In}, \mathrm{Mn}$, and $\mathrm{Cu}$ ) for $\mathrm{PDH}$.
These provide great opportunities for the utilization of Pt species at the atomic scale.

Metal oxides, including $\mathrm{VO}_{x^{-}}$and $\mathrm{GaO}_{x}$-based catalysts, are reported to be active for $\mathrm{PDH}$, which represent the most promising alternatives to $\mathrm{CrO}_{x}$ - and Pt-based catalysts. Their catalytic performances are strongly affected by the types of supports, promoters, preparation methods, and loading amounts. $\mathrm{VO}_{X^{-}}$ and $\mathrm{GaO}_{x}$-based catalysts with high surface areas, suitable acidities, fine dispersions, and moderate metal-supported interactions exhibit high PDH performances. A number of $\mathrm{VO}_{x^{-}}$and $\mathrm{GaO}_{x}$-based catalysts have been employed in PDH. However, their performances are still lower than those of $\mathrm{CrO}_{x^{-}}$and Pt-based catalysts. The development of new efficient methods to improve the stability of $\mathrm{VO}_{\mathrm{x}^{-}}$- and $\mathrm{GaO}_{x}$-based catalysts is still a great challenge. Furthermore, there are many different kinds of $\mathrm{V}$ (such as $\mathrm{V}^{5+}, \mathrm{V}^{4+}, \mathrm{V}^{3+}$, isolated $\mathrm{V}$, oligomeric $\mathrm{V}^{n+}$, and crystalline $\mathrm{V}_{2} \mathrm{O}_{5}$ ) and $\mathrm{Ga}$ (such as $\mathrm{Ga}^{3+},\left[\mathrm{GaH}_{2}\right]^{+},[\mathrm{GaH}]^{2+}$, and polymorphs of gallium oxides) species that exist on $\mathrm{VO}_{x^{-}}$and $\mathrm{GaO}_{x}$-based catalysts. Revealing the active sites and mechanisms of these catalysts is highly difficult.

Nanocarbons (such as OMCs, biomass-derived porous carbons, and MWCNTs) have also been reported to be active for PDH. Compared with noble metal and metal oxide catalysts, nanocarbons exhibit many advantages, such as high surface area, tunable nanoscale dimension, and abundant functional groups. The structure and surface functional groups can significantly affect their catalytic performance in PDH. In particular, nanocarbons with rich pores and abundant surface functional groups are active for PDH. However, there are many surface functional groups, such as 0-containing groups (ketones, carboxylic anhydrides, lactone, carboxylic acid, ether, phenol, etc.), $\mathrm{P}$-containing groups $\left(-\mathrm{P}=\mathrm{O}, \quad-\mathrm{PO}(\mathrm{OH})_{2}, \quad-\mathrm{OPO}(\mathrm{OH})_{2}\right.$, and $-\mathrm{P}(\mathrm{OH})_{2}$ ), N-containing groups (such as pyridine oxide, amide, amine, pyrrole, pyridine, and lactam), and other heteroatoms (B, F, Cl, etc.), in nanocarbons. Revealing the role of each functional group in $\mathrm{PDH}$ is extremely difficult. It is reported that defects, $\mathrm{C}=\mathrm{O}$, and $\mathrm{P}=\mathrm{O}$ are responsible for the high catalytic performance of nanocarbons in PDH. However, the catalytic mechanisms of these active sites are still debated. Theoretical calculations and simulations are therefore highly desired.

Additionally, some other supported metal oxides (such as $\mathrm{FeO}_{x}, \mathrm{CoO}_{x}, \mathrm{SnO}_{x}, \mathrm{ZnO}_{x}$, and $\mathrm{ZrO}_{2}$-based catalysts) have been studied for PDH. These have focused on the development of new preparation methods to synthesize alternative catalysts to Pt- and $\mathrm{CrO}_{x}$-based catalysts. In particular, some novel catalysts with single atoms have been synthesized. Their structural and textural properties, nature of active sites, and catalytic mechanisms have been investigated and identified. In some cases, their catalytic performance is comparable and/or much higher than those of Pt- and $\mathrm{CrO}_{x}$-based catalysts, which suggests that they are very promising PDH catalysts.

By reviewing the literature, it can be found that isolated and/or single atom catalysts exhibit promising performance in PDH through interaction between the support and the active metal centers, which results in improved stability and anti-coking capability. Even though some work has been carried out on single atom catalysts, more investigations are required 
to increase the loading amount and improve the performance of single atom catalysts. Particularly, surface organometallic method has been regarded as one of the most promising methods of synthesis of single atom catalysts. Typically, metal precursors with well-defined structures (metal + organic ligands) are grafted onto supports (such as $\mathrm{Al}_{2} \mathrm{O}_{3}, \mathrm{SiO}_{2}$, and zeolites), which result in single atom and/or double alloy atom catalysts. Owing to the well-defined structure of the active sites, the mechanisms of these catalysts can be easily identified.

Despite significant progress in the past few decades, $\mathrm{CrO}_{x}-$ and Pt-based catalysts are still the most widely used industrial PDH catalysts. These two catalyst systems generally suffer from serious coke formation and low stability. Improving their catalytic performance (including activity, selectivity, and stability) in PDH process is still the main target. Further, more detailed, systematic, and scientific studies on the roles of promoters, interactions between the active sites and supports, acidity of the support, and structural and electronic properties of $\mathrm{CrO}_{x^{-}}$ and Pt-based catalysts are highly desired. Alternatively, a number of metal oxides $\left(\mathrm{VO}_{x}, \mathrm{GaO}_{x}, \mathrm{FeO}_{x}, \mathrm{CoO}_{x}, \mathrm{SnO}_{x}, \mathrm{ZnO}_{x}\right.$, and $\mathrm{ZrO}_{x}$ ) and nanocarbons (mesoporous $\mathrm{C}, \mathrm{C}$ nanotubes, and biomass-derived $\mathrm{C}$ ) have been synthesized and utilized for $\mathrm{PDH}$, which exhibit performances comparable to those of $\mathrm{CrO}_{x^{-}}$and Pt-based catalysts. Among them, isolated Fe, Co, Sn, Zn, and $\mathrm{Zr}$ metals supported on $\mathrm{Al}_{2} \mathrm{O}_{3}, \mathrm{SiO}_{2}$, and zeolites represent highly promising catalysts for PDH. However, the performances (activity, selectivity, and stability) of these catalysts are still unsatisfactory, owing to the low stability and regenerability. Future research should focus on (i) developing new efficient synthesis methods to improve the catalyst stability, (ii) revealing the active sites and catalytic mechanisms, (iii) identifying the interplay between catalyst deactivation and regeneration, and (iv) developing in situ and/or operando spectroscopy techniques to monitor the changes occurring in the catalysts (in terms of structure and surface properties) during the PDH process.

\section{Acknowledgments}

This work was supported by the National Natural Science Foundation of China (21421001, 21573115), the Fundamental Research Funds for the Central Universities (63185015), and the Foundation of State Key Laboratory of High-Efficiency Utilization of Coal and Green Chemical Engineering (2017-K13).

\section{References}

[1] J. J. H. B. Sattler, J. Ruiz-Martinez, E. Santillan-Jimenez, B. M. Weckhuysen, Chem. Rev., 2014, 114, 10613-10653.

[2] M. A. Atanga, F. Rezaei, A. Jawad, M. Fitch, A. A. Rownaghi, Appl. Catal. B, 2018, 220, 429-445.

[3] Z. J. Zhao, C. C. Chiu, J. Gong, Chem. Sci., 2015, 6, 4403-4425.

[4] F. Cavani, N. Ballarini, A. Cericola, Catal. Today, 2007, 127, 113-131.

[5] L. Liu, Y. P. Zhu, M. Su, Z. Y. Yuan, ChemCatChem, 2015, 7, 2765-2787.

[6] D. S. Su, S. Perathoner, G. Centi, Chem. Rev., 2013, 113, 5782-5816.

[7] W. Qi, P. Yan, D. S. Su, Acc. Chem. Res., 2018, 51, 640-648.

[8] Z. Zhao, G. Ge, W. Li, X. Guo, G. Wang, Chin. J. Catal., 2016, 37, 644-670.

[9] I. Yarulina, K. De Wispelaere, S. Bailleul, J. Goetze, M. Radersma, E. Abou-Hamad, I. Vollmer, M. Goesten, B. Mezari, E. J. M. Hensen, J. S. Martínez-Espín, M. Morten, S. Mitchell, J. Perez-Ramirez, U. Olsbye, B. M. Weckhuysen, V. V. Speybroeck, F. Kapteijn, J. Gascon, Nat. Chem., 2018, 10, 804-812.

[10] J. Zhong, J. Han, Y. Wei, P. Tian, X. Guo, C. Song, Z. Liu, Catal. Sci. Technol., 2017, 7, 4905-4923.

[11] P. Munnik, P. E. de Jongh, K. P. de Jong, J. Am. Chem. Soc., 2014, $136,7333-7340$.

[12] A. Y. Khodakov, W. Chu, P. Fongarland, Chem. Rev., 2007, 107, 1692-1744.

[13] C. J. Weststrate, J. van de Loosdrecht, J. W. Niemantsverdriet, J.

\section{Graphical Abstract}

Chin. J. Catal., 2019, 40: 1233-1254 doi: S1872-2067(19)63360-7

\section{State-of-the-art catalysts for direct dehydrogenation of propane to propylene}

Zhong-Pan Hu, Dandan Yang, Zheng Wang, Zhong-Yong Yuan *

Nankai University;

Ningxia University

This review presents the state-of-the-art catalysts (including $\mathrm{Pt}, \mathrm{CrO}_{\mathrm{x}}$ $\mathrm{VO}_{\mathrm{x}}, \mathrm{GaO}_{\mathrm{x}}, \mathrm{ZnO}, \mathrm{FeO}_{\mathrm{x}}, \mathrm{CoO}_{\mathrm{x}}, \mathrm{SnO}_{\mathrm{x}}, \mathrm{ZrO}_{2}$-based catalysts, and nanocarbons) that have been reported in recent years for direct dehydrogenation of propane to propylene.

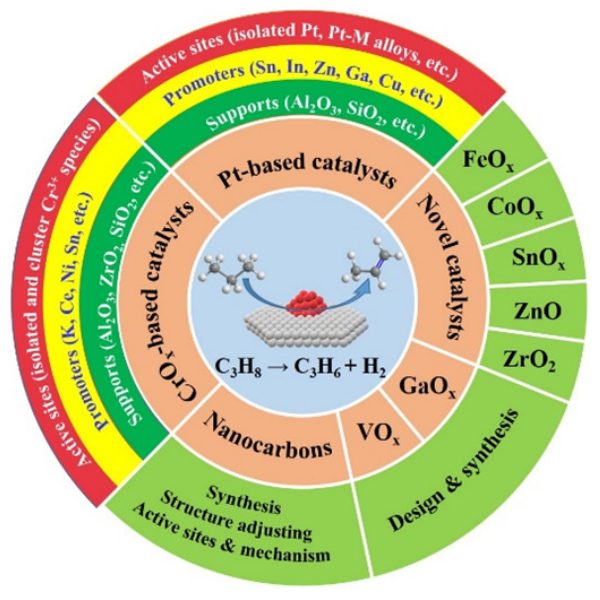


Catal., 2016, 342, 1-16.

[14] L. Shi, Y. Wang, B. Yan, W. Song, D. Shao, A. H. Lu, Chem. Commun., 2018, 54, 10936-10946.

[15] D. Chen, A. Holmen, Z. Sui, X. Zhou, Chin. J. Catal., 2014, 35, 824-841.

[16] I. Kainthla, J. T. Bhanushali, R. S. Keri, B. M. Nagaraja, Catal. Sci. Technol., 2015, 5, 5062-5076.

[17] Z. Nawaz, Rev. Chem. Eng., 2015, 31, 413-436.

[18] J. J. H. B. Sattler, I. D. Gonzalez-Jimenez, A. M. Mens, M. Arias, T. Visser, B. M. Weckhuysen, Chem. Commun., 2013, 49, 1518-1520.

[19] K. Searles, K. W. Chan, J. A. Mendes Burak, D. Zemlyanov, O. Safonova, C. Copéret, J. Am. Chem. Soc., 2018, 140, 11674-11679.

[20] J. Li, J. Li, Z. Zhao, X. Fan, J. Liu, Y. Wei, A. Duan, Z. Xie, Q. Liu, J. Catal., 2017, 352, 361-370.

[21] S. Sokolov, M. Stoyanova, U. Rodemerck, D. Linke, E. V. Kondratenko, J. Catal., 2012, 293, 67-75.

[22] H. Xiong, S. Lin, J. Goetze, P. Pletcher, H. Guo, L. Kovarik, K. Artyushkova, B. M. Weckhuysen, A. K. Datye, Angew. Chem. Int. Ed., 2017, 56, 8986-8991.

[23] J. J. H. B. Sattler, I. D. Gonzalez-Jimenez, L. Luo, B. A. Stears, A. Malek, D. G. Barton, B. A. Kilos, M. P. Kaminsky, T. W. G. M. Verhoeven, E. J. Koers, M. Baldus, B. M. Weckhuysen, Angew. Chem. Int. Ed., 2014, 53, 9251-9256.

[24] J. J. H. B. Sattler, A. M. Mens, B. M. Weckhuysen, ChemCatChem, 2014, 6, 3139-3145.

[25] J. McGregor, Z. Huang, E. P. Parrott, J. A. Zeitler, K. L. Nguyen, J. M. Rawson, A. Carley, T. W. Hansen, J. P. Tessonnier, D. S. Su, D. Teschner, E. M. Vass, A. Knop-Gericke, R. Schlögl, L. F. Gladden, J. Catal., 2010, 269, 329-339.

[26] Z. Lian, S. Ali, T. Liu, C. Si, B. Li, D. S. Su, ACS Catal., 2018, 8, 4694-4704.

[27] S. M. Airaksinen, M. A. Bañares, A. O. I. Krause, J. Catal., 2005, 230, 507-513.

[28] F. E. Frey, W. F. Huppke, Ind. Eng. Chem., 1933, 25, 54-59.

[29] W. Z. Lang, C. L. Hu, L. F. Chu, Y. J. Guo, RSC Adv., 2014, 4, 37107-37113.

[30] A. Węgrzyniak, S. Jarczewski, A. Węgrzynowicz, B. Michorczyk, P. Kuśtrowski, P. Michorczyk, Nanomaterials, 2017, 7, 249.

[31] M. S. Kumar, N. Hammer, M. Rønning, A. Holmen, D. Chen, J. C. Walmsley, G. Øye, J. Catal., 2009, 261, 116-128.

[32] V. Z. Fridman, R. Xing, M. Severance, Appl. Catal. A, 2016, 523, 39-53.

[33] J. Baek, H. J. Yun, D. Yun, Y. Choi, J. Yi, ACS Catal., 2012, 2, 1893-1903.

[34] T. P. Otroshchenko, U. Rodemerck, D. Linke, E. V. Kondratenko, J. Catal., 2017, 356, 197-205.

[35] A. Węgrzyniak, S. Jarczewski, A. Wach, E. Hędrzak, P. Kuśtrowski, P. Michorczyk, Appl. Catal. A, 2015, 508, 1-9.

[36] C. Copéret, D. P. Estes, K. Larmier, K. Searles, Chem. Rev., 2016, 116, 8463-8505.

[37] C. Copéret, F. Allouche, K. W. Chan, M. P. Conley, M. F. Delley, A. Fedorov, I. B. Moroz, V. Mougel, M. Pucino, K. Searles, K. Yamamoto, P. A. Zhizhko, Angew. Chem. Int. Ed., 2018, 57, 6398-6440.

[38] M. P. Conley, M. F. Delley, F. Núñez-Zarur, A. Comas-Vives, C. Copéret, Inorg. Chem., 2015, 54, 5065-5078.

[39] M. F. Delley, M. C. Silaghi, F. Nuñez-Zarur, K. V. Kovtunov, O. G. Salnikov, D. P. Estes, I. V. Koptyug, C. Copéret, Organometallics, 2016, 36, 234-244.

[40] M. G. Cutrufello, S. De Rossi, I. Ferino, R. Monaci, E. Rombi, V. Solinas, Thermochim. Acta, 2005, 434, 62-68.

[41] A. Węgrzyniak, A. Rokicińska, E. Hędrzak, B. Michorczyk, K. Zeńczak-Tomera, P. Kuśtrowski, P. Michorczyk, Catal. Sci. Tech- nol., 2017, 7, 6059-6068.

[42] T. H. Kim, M. Y. Gim, J. H. Song, W. C. Choi, Y. K. Park, U. G. Hong, D. S. Park, I. K. Song, Catal. Commun., 2017, 97, 37-41.

[43] S. Sim, S. Gong, J. Bae, Y. K. Park, J. Kim, W. C. Choi, D. S. Hong, I. K. Song, H. Seo, N. Y. Kang, S. Park, Mol. Catal., 2017, 436, 164-173.

[44] F. Cabrera, D. Ardissone, O. F. Gorriz, Catal. Today, 2008, 133-135, 800-804.

[45] P. P. Li, W. Z. Lang, K. Xia, L. Luan, X. Yan, Y. J. Guo, Appl. Catal. A, 2016, 522, 172-179.

[46] K. H. Kang, T. H. Kim, W. C. Choi, Y. K. Park, U. G. Hong, D. S. Park, C. J. Kim, I. K. Song, Catal. Commun., 2015, 72, 68-72.

[47] S. A. Dzhamalova, Russ. J. Appl. Chem., 2010, 83, 2152-2157.

[48] R. P. Dzhafarov, S. M. Gadzhizade, S. A. Dzhamalova, N. A. Aliev, A. A. Kasimov, Kinet. Catal., 2012, 53, 280-285.

[49] Q. Li, Z. Sui, X. Zhou, Y. Zhu, J. Zhou, D. Chen, Top. Catal., 2011, 54, 888-896.

[50] Y. L. Shan, T. Wang, Z. J. Sui, Y. A. Zhu, X. G. Zhou, Catal. Commun., 2016, 84, 85-88.

[51] Y. L. Shan, Y. A. Zhu, Z. J. Sui, D. Chen, X. G. Zhou, Catal. Sci. Technol,, 2015, 5, 3991-4000.

[52] J. Zhu, M. L. Yang, Y. Yu, Y. A. Zhu, Z. J. Sui, X. G. Zhou, A. Holmen, D. Chen, ACS Catal, 2015, 5, 6310-6319.

[53] S. Saerens, M. K. Sabbe, V. V. Galvita, E. A. Redekop, M. F. Reyniers, G. B. Marin, ACS Catal., 2017, 7, 7495-7508.

[54] Y. Zhang, Y. Zhou, J. Shi, S. Zhou, X. Sheng, Z. Zhang, S. Xiang, J. Mol. Catal. A, 2014, 381, 138-147.

[55] L. Shi, G. M. Deng, W. C. Li, S. Miao, Q. N. Wang, W. P. Zhang, A. H. Lu, Angew. Chem. Int. Ed., 2015, 54, 13994-13998.

[56] F. T. Zangeneh, S. Mehrazma, S. Sahebdelfar, Fuel Process. Technol., 2013, 109, 118-123.

[57] C. Sun, J. Luo, M. Cao, P. Zheng, G. Li, J. Bu, Z. Gao, S. Chen, X. Xie, J. Energy Chem., 2018, 27, 311-318.

[58] F. Jiang, L. Zeng, S. Li, G. Liu, S. Wang, J. Gong, ACS Catal., 2014, 5, 438-447.

[59] G. Siddiqi, P. Sun, V. Galvita, A. T. Bell, J. Catal., 2010, 274, 200-206.

[60] O. B. Belskaya, L. N. Stepanova, T. I. Gulyaeva, S. B. Erenburg, S. V. Trubina, K. Kvashnina, A. I. Nizovskii, A. V. Kalinkin, V. I. Zaikovskii, V. I. Bukhtiyarov, V. A. Likholobov, J. Catal., 2016, 341, 13-23.

[61] M. Filez, E. A. Redekop, H. Poelman, V. V. Galvita, M. Meledina, S. Turner, G. V. Tendeloo, C. Detavernier, G. B. Marin, Catal. Sci. Technol, 2016, 6, 1863-1869.

[62] K. Xia, W. Z. Lang, P. P. Li, L. L. Long, X. Yan, Y. J. Guo, Chem. Eng. J., 2016, 284, 1068-1079.

[63] T. Wang, F. Jiang, G. Liu, L. Zeng, Z. J. Zhao, J. Gong, AIChE J., 2016, $62,4365-4376$.

[64] L. L. Long, K. Xia, W. Z. Lang, L. L. Shen, Q. Yang, X. Yan, Y. J. Guo, J. Ind. Eng. Chem., 2017, 51, 271-280.

[65] L. Huang, B. Xu, L. Yang, Y. Fan, Catal. Commun., 2008, 9, 2593-2597.

[66] X. Fan, J. Li, Z. Zhao, Y. Wei, J. Liu, A. Duan, G. Jiang, Catal. Sci. Technol., 2015, 5, 339-350.

[67] Z. Nawaz, X. Tang, Y. Chu, F. Wei, Chin. J. Catal., 2010, 31, 552-556.

[68] Y. Zhang, Y. Zhou, L. Huang, S. Zhou, X. Sheng, Q. Wang, C. Zhang, Chem. Eng. J., 2015, 270, 352-361.

[69] A. Volynkin, M. Rønning, E. A. Blekkan, Top. Catal., 2015, 58, 854-865.

[70] J. Liu, Y. Yue, H. Liu, Z. Da, C. Liu, A. Ma, J. Rong, D. Su, X. Bao, H. Zheng, ACS Catal., 2017, 7, 3349-3355.

[71] J. Liu, J. Li, J. Rong, C. Liu, Z. Dai, J. Bao, Z. Da, H. Zheng, Appl. Surf. Sci., 2019, 464, 146-152.

[72] A. Iglesias-Juez, A. M. Beale, K. Maaijen, T. C. Weng, P. Glatzel, B. M. 
Weckhuysen, J. Catal., 2010, 276, 268-279.

[73] L. Nykänen, K. Honkala, ACS Catal., 2013, 3, 3026-3030.

[74] H. Zhu, D. H. Anjum, Q. Wang, E. Abou-Hamad, L. Emsley, H. Dong, P. Laveille, L. Li, A. K. Samal, J. M. Basset, J. Catal., 2014, 320, 52-62.

[75] Y. Zhu, Z. An, H. Song, X. Xiang, W. Yan, J. He, ACS Catal., 2017, 7, 6973-6978.

[76] F. T. Zangeneh, A. Taeb, K. Gholivand, S. Sahebdelfar, Appl. Surf. Sci., 2015, 357, 172-178.

[77] B. Li, Z. Xu, W. Chu, S. Luo, F. Jing, Chin. J. Catal., 2017, 38, 726-735.

[78] H. Zhou, J. Gong, B. Xu, L. Yu, Y. Fan, Appl. Catal. A, 2016, 527, 30-35.

[79] H. Zhou, J. Gong, B. Xu, S. Deng, Y. Ding, L. Yu, Y. Fan, Chin. J. Catal,, 2017, 38, 529-536.

[80] L. Deng, H. Miura, T. Shishido, Z. Wang, S. Hosokawa, K. Teramura, T. Tanaka, J. Catal., 2018, 365, 277-291.

[81] J. Camacho-Bunquin, M. S. Ferrandon, H. Sohn, A. J. Kropf, C. Yang, J. Wen, R. A. Hackler, C. Liu, G. Celik, C. L. Marshall, P. C. Stair, M. Delferro, ACS Catal., 2018, 8, 10058-10063.

[82] V. J. Cybulskis, B. C. Bukowski, H. T. Tseng, J. R. Gallagher, Z. Wu, E. Wegener, A. J. Kropf, B. Ravel, F. H. Ribeiro, J. Greeley, J. T. Miller, ACS Catal., 2017, 7, 4173-4181.

[83] C. Chen, M. Sun, Z. Hu, J. Ren, S. Zhang, Z. Y. Yuan, Catal. Sci. Technol, 2019, DOI: 10.1039/c9cy00237e.

[84] G. Liu, L. Zeng, Z. J. Zhao, H. Tian, T. Wu, J. Gong, ACS Catal., 2016, 6, 2158-2162.

[85] N. M. Schweitzer, B. Hu, U. Das, H. Kim, J. Greeley, L. A. Curtiss, P. C. Stair, J. T. Miller, A. S. Hock, ACS Catal., 2014, 4, 1091-1098.

[86] T. Gong, L. Qin, J. Lu, H. Feng, Phys. Chem. Chem. Phys., 2016, 18, 601-614.

[87] J. Camacho-Bunquin, P. Aich, M. Ferrandon, U. Das, A. Getsoian, U. Das, F. Dogan, L. A. Curtiss, J. T. Miller, C. L. Marshall, A. S. Hock, P. C. Stair, J. Catal., 2017, 345, 170-182.

[88] S. Zha, G. Sun, T. Wu, J. Zhao, Z. J. Zhao, J. Gong, Chem. Sci., 2018, 9, 3925-3931.

[89] P. Sun, G. Siddiqi, W. C. Vining, M. Chi, A. T. Bell, J. Catal,, 2011, $282,165-174$

[90] X. Liu, W. Z. Lang, L. L. Long, C. L. Hu, L. F. Chu, Y. J. Guo, Chem. Eng. J., 2014, 247, 183-192.

[91] L. L. Shen, K. Xia, W. Z. Lang, L. F. Chu, X. Yan, Y. J. Guo, Chem. Eng. J., 2017, 324, 336-346.

[92] G. Sun, Z. J. Zhao, R. Mu, S. Zha, L. Li, S. Chen, K. Zang, J. Luo, Z. Li, S. C. Purdy, A. J. Kropf, J. T. Miller, L. Zeng, J. Gong, Nat. Commun., 2018, 9, 4454.

[93] W. Cai, R. Mu, S. Zha, G. Sun, S. Chen, Z. J. Zhao, H. Li, H. Tian, Y. Tang, F. Tao, L. Zeng, L. Gong, Sci. Adv., 2018, 4, eaar5418.

[94] Z. Wu, B. C. Bukowski, Z. Li, C. Milligan, L. Zhou, T. Ma, Y. Wu, Y. Ren, F. H. Ribeiro, W. N. Delgass, J. Greeley, G. Zhang, J. T. Miller, J. Am. Chem. Soc., 2018, 140, 14870-14877.

[95] G. Q. Ren, G. X. Pei, Y. J. Ren, K. P. Liu, Z. Q. Chen, J. Y. Yang, Y. Su, X. Y. Liu, W. Z. Li, T. Zhang, J. Catal., 2018, 366, 115-126.

[96] R. R. Langeslay, D. M. Kaphan, C. L. Marshall, P. C. Stair, A. P. Sattelberger, M. Delferro, Chem. Rev., 2019, 119, 2128-2191.

[97] S. Sokolov, M. Stoyanova, U. Rodemerck, D. Linke, E. V. Kondratenko, Catal. Sci. Technol., 2014, 4, 1323-1332.

[98] S. Sokolov, V. Y. Bychkov, M. Stoyanova, U. Rodemerck, U. Bentrup, D. Linke, Y. P. Tyulenin, V. N. Korchak, E. V. Kondratenko, ChemCatChem, 2015, 7, 1691-1700.

[99] G. Liu, Z. J. Zhao, T. Wu, L. Zeng, J. Gong, ACS Catal., 2016, 6, 5207-5214.

[100] P. Hu, W. Z. Lang, X. Yan, L. F. Chu, Y. J. Guo, J. Catal., 2018, 358,
108-117.

[101] P. Bai, Z. Ma, T. Li, Y. Tian, Z. Zhang, Z. Zhong, W. Xing, P. Wu, X. Liu, Z. Yan, ACS Appl. Mater. Interfaces, 2016, 8, 25979-25990.

[102] U. Rodemerck, M. Stoyanova, E. V. Kondratenko, D. Linke, J. Catal., 2017, 352, 256-263.

[103] T. Wu, G. Liu, L. Zeng, G. Sun, S. Chen, R. Mu, S. A. Gbonfoun, Z. J. Zhao, J. Gong, AIChE J., 2017, 63, 4911-4919.

[104] Z. J. Zhao, T. Wu, C. Xiong, G. Sun, R. Mu, L. Zeng, J. Gong, Angew. Chem. Int. Ed., 2018, 57, 6791-6795.

[105] B. Zheng, W. Hua, Y. Yue, Z. Gao, J. Catal., 2005, 232, 143-151.

[106] C. T. Shao, W. Z. Lang, X. Yan, Y. J. Guo, RSC Adv., 2017, 7, 4710-4723.

[107] M. Chen, J. Xu, F. Z. Su, Y. M. Liu, Y. Cao, H. Y. He, K. N. Fan, J. Catal., 2008, 256, 293-300.

[108] K. Searles, G. Siddiqi, O. V. Safonova, C. Copéret, Chem. Sci., 2017, 8, 2661-2666.

[109] K. C. Szeto, Z. R. Jones, N. Merle, C. Rios, A. Gallo, F. Le Quemener, L. Delevoye, R. M. Gauvin, S. L. Scott, M. Taoufik, ACS Catal., 2018, 8, 7566-7577.

[110] Y. Ren, J. Wang, W. Hua, Y. Yue, Z. Gao, J. Ind. Eng. Chem., 2012, $18,731-736$

[111] W. G. Kim, J. So, S. W. Choi, Y. Liu, R. S. Dixit, C. Sievers, D. S. Sholl, S. Nair, C. W. Jones, Chem. Mater., 2017, 29, 7213-7222.

[112] S. W. Choi, W. G. Kim, J. S. So, J. S. Moore, Y. Liu, R. S. Dixit, J. G. Pendergast, C. Sievers, D. S. Sholl, S. Nair, C. W. Jones, J. Catal., 2017, 345, 113-123.

[113] M. W. Schreiber, C. P. Plaisance, M. Baumgärtl, K. Reuter, A. Jentys, R. Bermejo-Deval, J. A. Lercher, J. Am. Chem. Soc., 2018, $140,4849-4859$.

[114] E. Mansoor, M. Head-Gordon, A. T. Bell, ACS Catal., 2018, 8, 6146-6162.

[115] N. Phadke, J. Van der Mynsbrugge, E. Mansoor, A. Getsoian, M. Head-Gordon, A. T. Bell, ACS Catal., 2018, 8, 6106-6126.

[116] S. Tan, L. B. Gil, N. Subramanian, D. S. Sholl, S. Nair, C. W. Jones, J. S. Moore, Y. Liu, R. S. Dixit, J. G. Pendergast, Appl. Catal. A, 2015, 498, 167-175.

[117] S. Tan, S. J. Kim, J. S. Moore, Y. Liu, R. S. Dixit, J. G. Pendergast, D. S Sholl, S. Nair, C. W. Jones, ChemCatChem, 2016, 8, 214-221.

[118] X. X. Hou, Q. F. Deng, T. Z. Ren, Z. Y. Yuan, Environ. Sci. Pollut. Res., 2013, 20, 8521-8534.

[119] L. Liu, Q. F. Deng, T. Y. Ma, X. Z. Lin, X. X. Hou, Y. P. Liu, Z. Y. Yuan, J. Mater. Chem., 2011, 21, 16001-16009.

[120] L. Liu, Q. F. Deng, X. X. Hou, Z. Y. Yuan, J. Mater. Chem., 2012, 22, 15540-15548.

[121] J. T. Ren, G. G. Yuan, C. C. Weng, L. Chen, Z. Y. Yuan, ChemCatChem, 2018, 10, 1-10.

[122] J. T. Ren, Z. Y. Yuan, ChemCatChem, 2018, 10, 3260-3268.

[123] M. H. Sun, S. Z. Huang, L. H. Chen, Y. Li, X. Y. Yang, Z. Y. Yuan, B. L. Su, Chem. Soc. Rev., 2016, 45, 3479-3563.

[124] T. Y. Ma, L. Liu, Z. Y. Yuan, Chem. Soc. Rev., 2013, 42, 3977-4003.

[125] J. T. Ren, G. G. Yuan, C. C. Weng, Z. Y. Yuan, Electrochim. Acta, 2018, 261, 454-463.

[126] J. T. Ren, Y. J. Song, Z. Y. Yuan, J. Energy Chem., 2019, 32, 78-84.

[127] J. T. Ren, L. Chen, C. C. Weng, G. G. Yuan, Z. Y. Yuan, ACS Appl. Mater. Interfaces, 2018, 10, 33276-33286.

[128] J. T. Ren, G. G. Yuan, C. C. Weng, Z. Y. Yuan, ACS Sustainable Chem. Eng., 2017, 6, 707-718.

[129] H. Li, Y. Sun, Z. Y. Yuan, Y. P. Zhu, T. Y. Ma, Angew. Chem. Int. Ed., 2018, 57, 3222-3227.

[130] Y. P. Zhu, T. Y. Ma, T. Z. Ren, J. Li, G. H. Du, Z. Y. Yuan, Appl. Catal. $B, 2014,156-157,44-52$.

[131] M. Chen, L. L. Shao, X. Qian, T. Z. Ren, Z. Y. Yuan, J. Mater. Chem. C, 
2014, 2, 10312-10321.

[132] M. Chen, L. L. Shao, Z. M. Gao, T. Z. Ren, Z. Y. Yuan, J. Power Sources, 2015, 286, 82-90.

[133] L. Liu, Q. F. Deng, B. Agula, X. Zhao, T. Z. Ren, Z. Y. Yuan, Chem. Commun., 2011, 47, 8334-8336.

[134] Z. P. Hu, J. T. Ren, D. Yang, Z. Wang, Z. Y. Yuan, Chin. J. Catal,, 2019, DOI: S1872-2067(19)63334-6.

[135] L. Liu, Q. F. Deng, B. Agula, T. Z. Ren, Y. P. Liu, B. Zhaorigetu, Z. Y. Yuan, Catal. Today, 2012, 186, 35-41.

[136] R. Wang, X. Sun, B. Zhang, X. Sun, D. Su, Chem. Eur. J., 2014, 20, 6324-6331.

[137] L. Liu, Q. F. Deng, Y. P. Liu, T. Z. Ren, Z. Y. Yuan, Catal. Commun., 2011, 16, 81-85.

[138] Y. Song, G. Liu, Z. Y. Yuan, RSC Adv., 2016, 6, 94636-94642.

[139] L. Li, W. Zhu, Y. Liu, L. Shi, H. Liu, Y. Ni, S. Liu, H. Zhou, Z. Liu, RSC Adv., 2015, 5, 56304-56310.

[140] Z. P. Hu, H. Zhao, C. Chen, Z. Y. Yuan, Catal. Today, 2018, 316, 214-222.

[141] Z. P. Hu, L. F. Zhang, Z. Wang, Z. Y. Yuan, J. Chem. Technol. Biotechnol, 2018, 93, 3410-3417.

[142] Z. P. Hu, C. Chen, J. T. Ren, Z. Y. Yuan, Appl. Catal. A, 2018, 559, 85-93.

[143] J. L. Figueiredo, M. F. R. Pereira, Catal. Today, 2010, 150, 2-7.

[144] J. Deng, M. Li, Y. Wang, Green Chem., 2016, 18, 4824-4854.

[145] X. Sun, Y. Ding, B. Zhang, R. Huang, D. Chen, D. S. Su, ACS Catal., 2015, 5, 2436-2444.

[146] I. Gerber, M. Oubenali, R. Bacsa, J. Durand, A. Gonçalves, M. F. R. Pereira, F. Jolibois, L. Perrin, R. Poteau, P. Serp, Chem. Eur. J., 2011, 17, 11467-11477.

[147] Y. P. Zhu, Y. Liu, Y. P. Liu, T. Z. Ren, T. Chen, Z. Y. Yuan, ChemCatChem, 2015, 7, 2903-2909.

[148] Y. P. Zhu, Y. Liu, Y. P. Liu, T. Z. Ren, G. H. Du, T. Chen, Z. Y. Yuan, J. Mater. Chem. A, 2015, 3, 11725-11729.

[149] Y. P. Zhu, Y. P. Liu, Z. Y. Yuan, Chem. Commun., 2016, 52, 2118-2121.

[150] Y. N. Sun, L. Tao, T. You, C., Li, H. Shan, Chem. Eng. J., 2014, 244, 145-151.
[151] Y. Sun, Y. Wu, H. Shan, G. Wang, C. Li, Catal. Sci. Technol., 2015, 5, 1290-1298.

[152] Y. Sun, Y. Wu, L. Tao, H. Shan, G. Wang, C. Li, J. Mol. Catal. A, 2015, $397,120-126$.

[153] J. H. Yun, R. F. Lobo, J. Catal., 2014, 312, 263-270.

[154] B. Hu, N. M. Schweitzer, G. Zhang, S. J. Kraft, D. J. Childers, M. P. Lanci, J. T. Miller, A. S. Hock, ACS Catal., 2015, 5, 3494-3503.

[155] S. Tan, B. Hu, W. G. Kim, S. H. Pang, J. S. Moore, Y. Liu, R. S. Dixit, J. G. Pendergast, D. S. Sholl, S. Nair, C. W. Jones, ACS Catal., 2016, 6, 5673-5683.

[156] B. Hu, N. M. Schweitzer, U. Das, H. Kim, J. Niklas, O. Poluektov, L. A. Curtiss, P. C. Stair, J. T. Miller, A. S. Hock, J. Catal., 2015, 322, 24-37.

[157] B. Hu, W. G. Kim, T. P. Sulmonetti, M. L. Sarazen, S. Tan, J. So, Y. Liu, R. S. Dixit, S. Nair, C. W. Jones, ChemCatChem, 2017, 9 , 3330-3337.

[158] Y. Zhao, H. Sohn, B. Hu, J. Niklas, O. G. Poluektov, J. Tian, M. Delferro, A. S. Hock, ACS Omega, 2018, 3, 11117-11127.

[159] X. Li, P. Wang, H. Wang, C. Li, Appl. Surf. Sci., 2018, 441, 688-693.

[160] Y. N. Sun, Y. N. Gao, Y. Wu, H. Shan, G. Wang, C. Li, Catal. Commun., 2015, 60, 42-45.

[161] G. Wang, H. Zhang, H. Wang, Q. Zhu, C. Li, H. Shan, J. Catal., 2016, 344, 606-608.

[162] G. Wang, H. Zhang, Q. Zhu, X. Zhu, X. Li, H. Wang, C. Li, H. Shan, J. Catal., 2017, 351, 90-94.

[163] C. Chen, Z. Hu, J. Ren, S. Zhang, Z. Wang, Z. Y. Yuan, ChemCatChem, 2019, 11, 868-877.

[164] T. Otroshchenko, S. Sokolov, M. Stoyanova, V. A. Kondratenko, U. Rodemerck, D. Linke, E. V. Kondratenko, Angew. Chem. Int. Ed., 2015, 54, 15880-15883.

[165] T. Otroshchenko, V. A. Kondratenko, U. Rodemerck, D. Linke, E. V. Kondratenko, J. Catal., 2017, 348, 282-290.

[166] Y. Zhang, Y. Zhao, T. Otroshchenko, H. Lund, M. M. Pohl, U. Rodemerck, D. Linke, H. Jiao, G. Jiang, E. V. Kondratenko, Nat. Commun., 2018, 9, 3794.

[167] T. P. Otroshchenko, V. A. Kondratenko, U. Rodemerck, D. Linke, E. V. Kondratenko, Catal. Sci. Technol., 2017, 7, 4499-4510.

\title{
丙烷直接脱氢催化剂的研究进展
}

\author{
胡忠攀 ${ }^{\mathrm{a}}$ ，杨丹丹 ${ }^{\mathrm{a}}$ ，王 政 ${ }^{\mathrm{b}}$ ，袁忠勇 ${ }^{\mathrm{a},}{ }^{*}$ \\ a南开大学材料科学与工程学院新催化材料科学研究所, 先进能源材料化学教育部重点实验室, 天津 300350 \\ $\mathrm{b}^{\mathrm{j}}$ 夏大学化学化工学院, 省部共建煤炭高效利用与绿色化工国家重点实验室, 宁夏银川750021
}

摘要: 丙烯是一种重要化工原料, 可以用于生产聚丙烯、丙烯腈、丙烯酸、甘油及异丙醇等化学品. 近年来, 随着丙烯下游 产品需求量的增加, 传统丙烯生产技术(石油催化裂解、石脑油催化裂化)难以满足日益增长的丙烯需求, 寻求新的丙烯生产 技术成为石油化工行业的重要趋势. 另外, 由于美国页岩气开采技术日益成熟, 大量廉价的丙烷被开采出来. 丙烷直接脱 氢制丙烯成本大大降低, 并逐渐成为丙烯生产来源的一个重要方面. 丙烷脱氢工艺中最重要的就是催化剂的制备和研究, 常见的丙烷脱氢催化剂为 $\mathrm{CrO}_{x}$ 基催化剂和 $\mathrm{Pt}$ 基催化剂体系, 并被广泛应用于工业丙烷脱氢体系. 但是, $\mathrm{Cr}$ 基催化剂积碳严 重, 需要反复再生; 而Pt基催化剂价格昂贵, 且Pt颗粒容易发生团聚而发生不可逆失活. 因此, 提高现有 $\mathrm{CrO}_{\mathrm{x}}$ 基和Pt基催化 剂的稳定性或开发新型替代型丙烷脱氢催化剂成为提高丙烷脱氢工艺的关键.

本文综述了近年来丙烷直接脱氢制丙烯催化剂的研究进展, 详细讨论了不同催化剂(包括 $\mathrm{Pt}, \mathrm{CrO}_{x}, \mathrm{VO}_{x}, \mathrm{GaO}_{x}, \mathrm{ZnO}$, $\mathrm{FeO}_{x}, \mathrm{CoO}_{x}, \mathrm{SnO}_{x}, \mathrm{ZrO}_{2}$ 基催化剂和碳基催化剂)的活性位点、催化机理及助剂类型和载体种类等对催化剂性能的影响. 研 究表明, 丙烷脱氢催化剂的催化性能与活性物种的分散性和催化剂酸性关系很大. 一般而言, 活性物种分散性越高, 催化 剂的催化性能越好. 而酸性过高会影响丙烯的脱附过程, 因而会导致丙烷的深度脱氢、裂解或积碳的形成. 因此, 提高活 性位的分散性和调节催化剂酸性是目前丙烷脱氢催化剂研究的重要方面. 最近的一些研究主要集中在制备单分散(单原 子)或双原子合金催化剂用于丙烷脱氢, 大大提高催化剂的稳定性. 
目前, $\mathrm{CrO}_{x}$ 基和Pt基催化剂仍是丙烷脱氢反应的主要催化剂, 提高它们的活性、稳定性、选择性和抗积碳能力仍是丙 烷脱氢工艺研究的重要方面. 另外, 一些新型负载型金属氧化物(如 $\mathrm{VO}_{x}, \mathrm{GaO}_{x}, \mathrm{FeO}_{x}, \mathrm{CoO}_{x}, \mathrm{SnO}_{x}, \mathrm{ZnO}_{x}, \mathrm{ZrO}_{x}$ ) 和纳米碳材料 (介孔碳、碳纳米管和生物质碳)被发现是良好的丙烷脱氢催化剂. 但是, 这些催化剂也面临失活严重和循环性差等问题. 因 此, 未来的研究目标需要集中在以下几方面: (1)开发新型制备工艺, 提高催化剂稳定性; (2)明确催化剂活性位点、催化机理 和构效关系; (3)明确催化剂失活和再生循环机制; (4)发展原位或operando技术监测丙烷脱氢催化剂的实时变化情况.

关键词: 丙烷脱氢; 丙烯; 非均相催化剂; 活性位; 催化机理

收稿日期: 2019-01-28. 接受日期: 2019-03-20. 出版日期: 2019-09-05.

*通讯联系人. 电话/传真: (022)23509610; 电子信箱: zyyuan@nankai.edu.cn

基金来源：国家自然科学基金(21421001，21573115); 中央高校基本科研业务费专项资金 (63185015); 煤炭高效利用与绿色化工 国家重点实验室基金(2017-K13).

本文的电子版全文由Elsevier出版社在ScienceDirect上出版(http://www.sciencedirect.com/science/journal/18722067). 